

\section{DISCLAIMER}

This report was prepared as an account of work sponsored by an agency of the United States Government. Neither the United States Government nor any agency Thereof, nor any of their employees, makes any warranty, express or implied, or assumes any legal liability or responsibility for the accuracy, completeness, or usefulness of any information, apparatus, product, or process disclosed, or represents that its use would not infringe privately owned rights. Reference herein to any specific commercial product, process, or service by trade name, trademark, manufacturer, or otherwise does not necessarily constitute or imply its endorsement, recommendation, or favoring by the United States Government or any agency thereof. The views and opinions of authors expressed herein do not necessarily state or reflect those of the United States Government or any agency thereof. 


\section{DISCLAIMER}

Portions of this document may be illegible in electronic image products. Images are produced from the best available original document. 


\section{LEGAL NOTICE}

This report was prepared as on occount of Government sponsored work. Neither the United States nor the Commission, nor any person acting on behalf of the Commission:

A. Makes any warranty or representation expressed or implied, with respect to the accu. racy, completeness, or usefulness of the information contained in this report, or that the use of any information, opparatus, method, or process disclosed in this report may not infringe privately owned rights; or

B. Assumes any liabilities with respect to the use of, or for damages resulting from. the use of any information, apporatus, method, or process disclosed in this report.

As used in the above, "person acting on behalf of the commission" includes any employee or contractor of the Commission, or employee of such contractor, to the extent that such employee or controctor of the Commission, or employee of such contractor prepores disseminates, or provides access to, any information pursuant to his employment or contract with the Commission, or his employment with such contractor. 


\title{
SUMMARY OF THE APDA SODIUM TECHNOLOGY PROGRAM
}

\author{
J. E. Meyers
}

United States Atomic Energy Commission

Contract No. AT(11-1)-865

Project Agreement No. 11

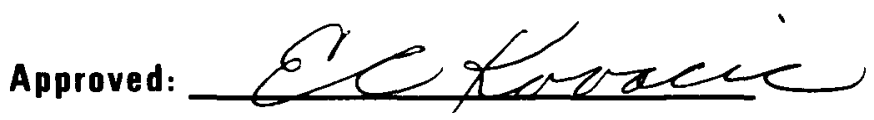

E. C. Kovacic

Senior Project Engineer

APDA 
This document summarizes an eight-year program conducted in the APDA Sodium Technology Loop in the following areas of sodium technology:

- Impurity monitoring devices such as the UKAEA Rhometer, the UNC oxygen meter, the APDA hydrogen detector, and the APDA variable-orifice plugging meter

- Impurity removal processes such as cold-trapping, hot-trapping, and operation of the APDA-developed sodium centrifuge

- The physical and chemical behavior in sodium of impurities such as hydrogen and sodium carbonate

- Sampling and analysis procedures, including a sampling reliability study for oxygen and hydrogen; a round robin program for measuring oxygen in sodium; a uranium gettering technique for measuring the oxygen content of sodium; and analytical methods for determining oxygen, total carbon, carbonate carbon, and hydrogen. 
LIST OF ILLUSTRATIONS $\ldots \ldots \ldots \ldots \ldots \ldots \ldots \ldots \ldots \ldots \ldots \ldots \ldots \ldots \ldots$

LIST OF TABLES $\ldots \ldots \ldots \ldots \ldots \ldots \ldots \ldots \ldots \ldots \ldots \ldots \ldots \ldots \ldots \ldots \ldots$

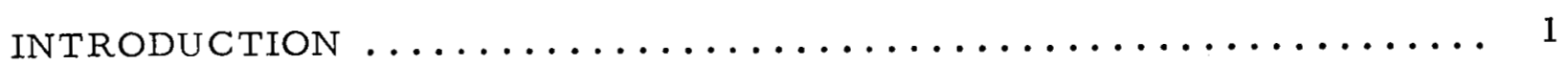

I. IMPURITY MONITORING DEVICES $\ldots \ldots \ldots \ldots \ldots \ldots \ldots \ldots \ldots$

A. RHOMETER ......................... 7

B. OXYGEN METER ....................... 13

C. HYDROGEN METER ....................... 19

D. PLUGGING METER ...................... 25

II. IMPURITY REMOVAL PROCESSES ............... 27

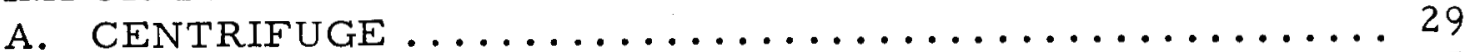

B. MOVABLE BED GETTERING ................... 35

C. COLD TRAPPING ......................... 37

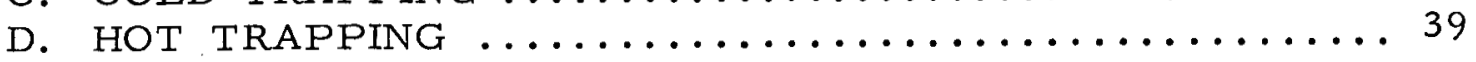

III. PHYSICAL AND CHEMICAL BEHAVIOR OF

SODIUM IMPURITIES $\ldots \ldots \ldots \ldots \ldots \ldots \ldots \ldots \ldots \ldots \ldots \ldots . \ldots \ldots$

A. THE SOLUBILITY OF HYDROGEN IN SODIUM ........4 43

B. THE SOLUBILITY OF SODIUM CARBONATE IN SODIUM.. 49

C. COVER GAS IMPURITIES - HYDROGEN GETTERING IN GAS SAMPLE LINES .................. 51

IV. SAMPLING AND ANALYSIS OF SODIUM $\ldots \ldots \ldots \ldots \ldots \ldots \ldots$

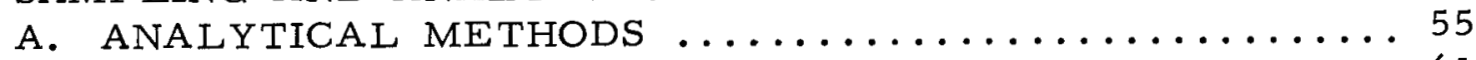

B. SAMPLING RELIABILITY STUDIES .............6 


\section{LIST OF ILLUSTRATIONS}

Figure No.

$\underline{\text { Page }}$

1 Schematic Diagram of Sodium Technology Loop .......... 3

2 The APDA Sodium Technology Test Loop .............. 4

3 Electronic Components of Rhometer Automatic

Temperature-Compensating System .............. 10

4 Recorder Trace of Rhometer Response to Xenon Injection .... 11

5 Response of Automatic Temperature-Compensated

Prototype Rhometer to Injections of Hydrogen Gas in Sodium . 12

6 Response of Oxygen Meter to Injections of 16 PPM Oxygen as Sodium Monoxide....................... 16

$7 \quad$ Basic Circuit of Oxygen Meter $\ldots \ldots \ldots \ldots \ldots \ldots \ldots \ldots$

$8 \quad$ APDA Hydrogen Detector Coil $\ldots \ldots \ldots \ldots \ldots \ldots \ldots \ldots \ldots$

9 Hydrogen Meter Response to Water Injections .......... 23

10 Cross Section of Sodium Centrifuge ............... 32

11 Sodium Technology and Centrifuge Loop ............. 33

12 Typical Sealed Nickel Capsule and Quartz Holder ........44

13 Schematic of Phase-I System-Pressure $<1 \mathrm{~mm} \ldots \ldots \ldots 5$

14 Hydrogen Solubility in Liquid Sodium $\ldots \ldots \ldots \ldots \ldots$

15 Solubility of Hydrogen in Sodium as a Function of

Temperature ......................... 47

16 Equilibrium Hydrogen Pressure for Saturated Sodium as a

Function of Temperature ................... 48

17 Arrangement of the Gas Sample Line for the Sodium

Technology Loop ....................... 52

18 Reflux Vessel for Hydrogen Determination ............59 


\section{LIST OF ILLUSTRATIONS (Continued)}

Figure No.

$\underline{\text { Page }}$

19 Combustion Train for Determining Carbon in Sodium Metal... 60

20 Oxygen Concentration Versus Site Location for Samples from Station 1 - Nonpinched Sample Tube, High-Level Oxygen 65

21 Oxygen Concentration Versus Site Location for Samples from Station 2 - Nonpinched Sample Tube, High-Level Oxygen ... 66

22 Relative Standard Deviation Versus Oxygen Concentration for Pinched and Nonpinched Sample Tubes from Station 1 ...... 67

23 Capsules Prepared by the APDA Laboratory for ASTM Round Robin Analysis ....................668

24 Sample Tube Site Averages - Station $2 \ldots \ldots \ldots \ldots \ldots$

\section{LIST OF TABLES}

Table No.

Page

1 Test Conditions for Uranium Gettering Experiments ....... 56

2 Data from Hydrogen Sampling Reliability Studies . . . . . . . . . 64 


\section{INTRODUCTION}

\section{A. BACKGROUND}

In 1962, a 4-inch sodium loop consisting of a plugging meter, retention tank, cold trap, and zirconium-packed hot trap was built primarily for use as a test facility in a program of evaluating the Blake sodium resistivity meter, or Rhometer, under contract agreement with the U. S. Atomic Energy Commission. The evaluation program was later broadened to include other moni toring devices such as a variable-orifice plugging meter, UNC oxygen meters, and an in-line hydrogen detector.

In 1963, a gas chromatograph and an injection port for the introduction of solid impurities into the loop sodium were added on the loop.

In 1965, the scope of work was further broadened to include (1) the development and refinement of analytical techniques for the quantitative determination of impurities in sodium, (2) investigation of the chemical and physical behavior of impurities in sodium, (3) the development and evaluation of in instruments for the detection and determination of impurities in sodium, and (4) the development and evaluation of sodium purification techniques. At that time, the loop capability was further enhanced by the addition of a 1 -inch loop equipped with a thermal decomposition tank, a filter cascade, two hydroclones, a through-flow sodium sampling station, two Rhometers, and four UNC oxygen meters.

In 1967, two major improvements were made to the Sodium Technology Loop: a cold trap was installed in the 1 -inch loop for performance evaluation, and an inert-atmosphere glove box was enclosed around the new sodium sampling and impurity injection stations to prevent atmospheric contamination of sodium samples and the chemical impurities being injected into the loop. At that time also, refinements were made to the loop heater circuits to obtain better temperature control and to eliminate impurity hideout and feedback; packed valves were replaced with bellows seal valves to prevent contamination of the sodium.

In 1968, improvements to the test facility included automatic control of loop temperatures, an automatic flow control system, and a continuous gas chromatograph. In 1969 , a sodium centrifuge which had been previously evaluated in a nonsodium environment was installed in the Sodium Technology Loop for performance evaluation in a sodium system. The APDA-designed hydrogen detector was installed on a bypass section of the 1 -inch loop and connected to the 1 -inch loop by an economizer. This installation includes a flowmeter, diffusion coil for the injection of hydrogen, and a precision heater to maintain the detector at $900 \mathrm{~F}$. 
As an adjunct to the Sodium Technology Loop as well as for fundamental research in the area of sodium technology, a modern chemistry laboratory capable of handling radioactive sodium samples was built. The laboratory equipment includes gas chromatographs and recorders, spectrophotometers, metallurgical and stereo microscopes, high-vacuum glass racks, a sodium still, a sodium purification system, specialized dry boxes and gas purification system, combustion furnaces, induction furnaces, vacuum ovens, optical pyrometers, radiochemical laboratory hoods, and assorted ventilation systems.

The additions and modifications over an 8 -year period have resulted in a reliable and efficient facility for research and development in the field of sodium technology. The APDA Sodium Technology Loop is shown schematically and photographically in Figures 1 and 2. The work carried out in this facility and summarized herein falls into the following categories:

- Evaluation of impurity monitoring devices: Rhometers for detecting a variety of impurities, oxygen and hydrogen meters, and plugging meters

- Impurity removal processes such as cold-trapping, hot-trapping, and operation of the APDA-developed sodium centrifuge

- The physical and chemical behavior of such impurities as hydrogen and sodium carbonate

- Sampling and analysis procedures, including a sampling reliability study, a round robin program for measuring oxygen in sodium, a uranium gettering technique for oxygen, and analysis techniques for oxygen, carbon, and hydrogen. 


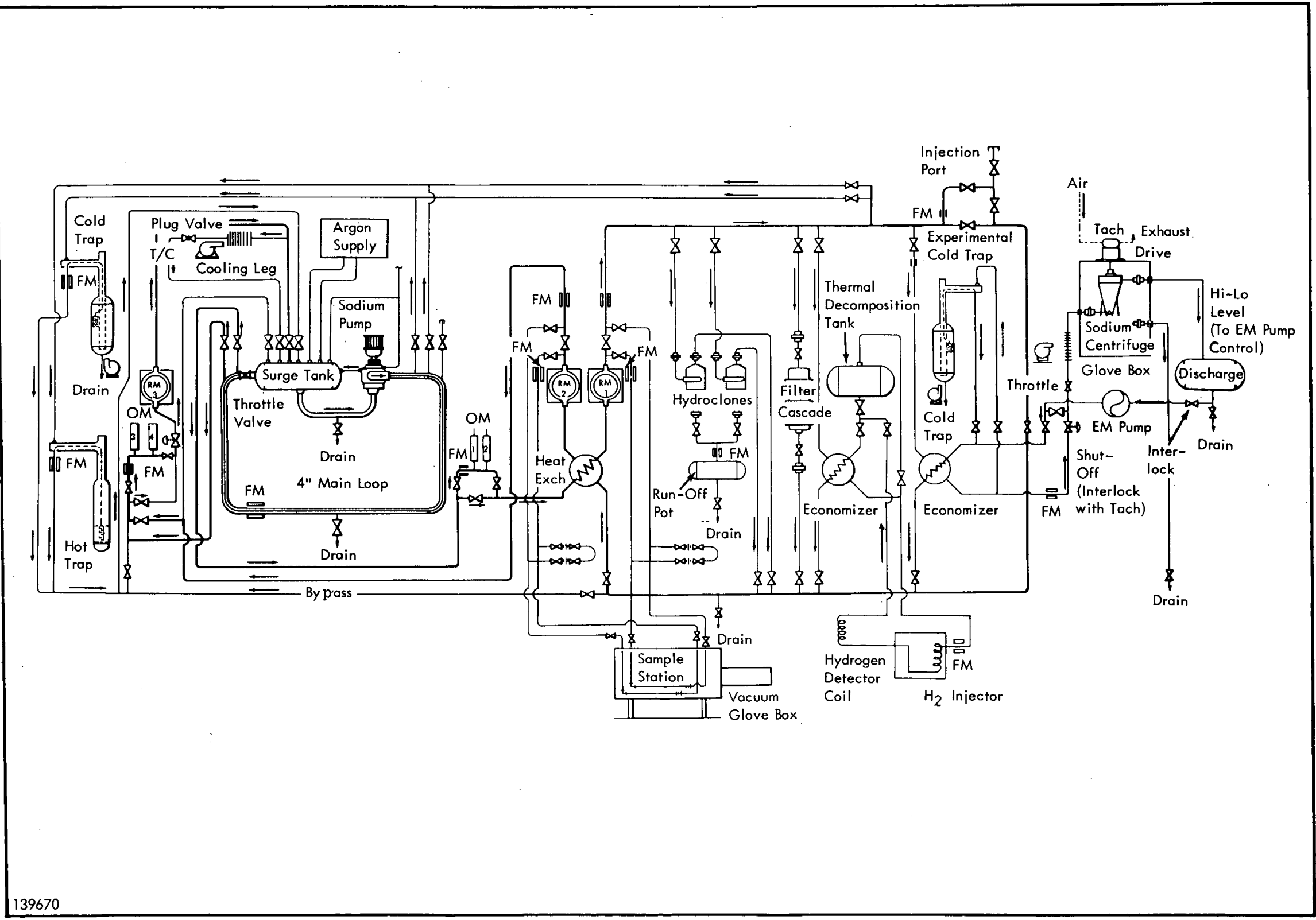

FIG. 1 SCHEMATIC DIAGRAM OF SODIUM TECHNOLOGY LOOP 


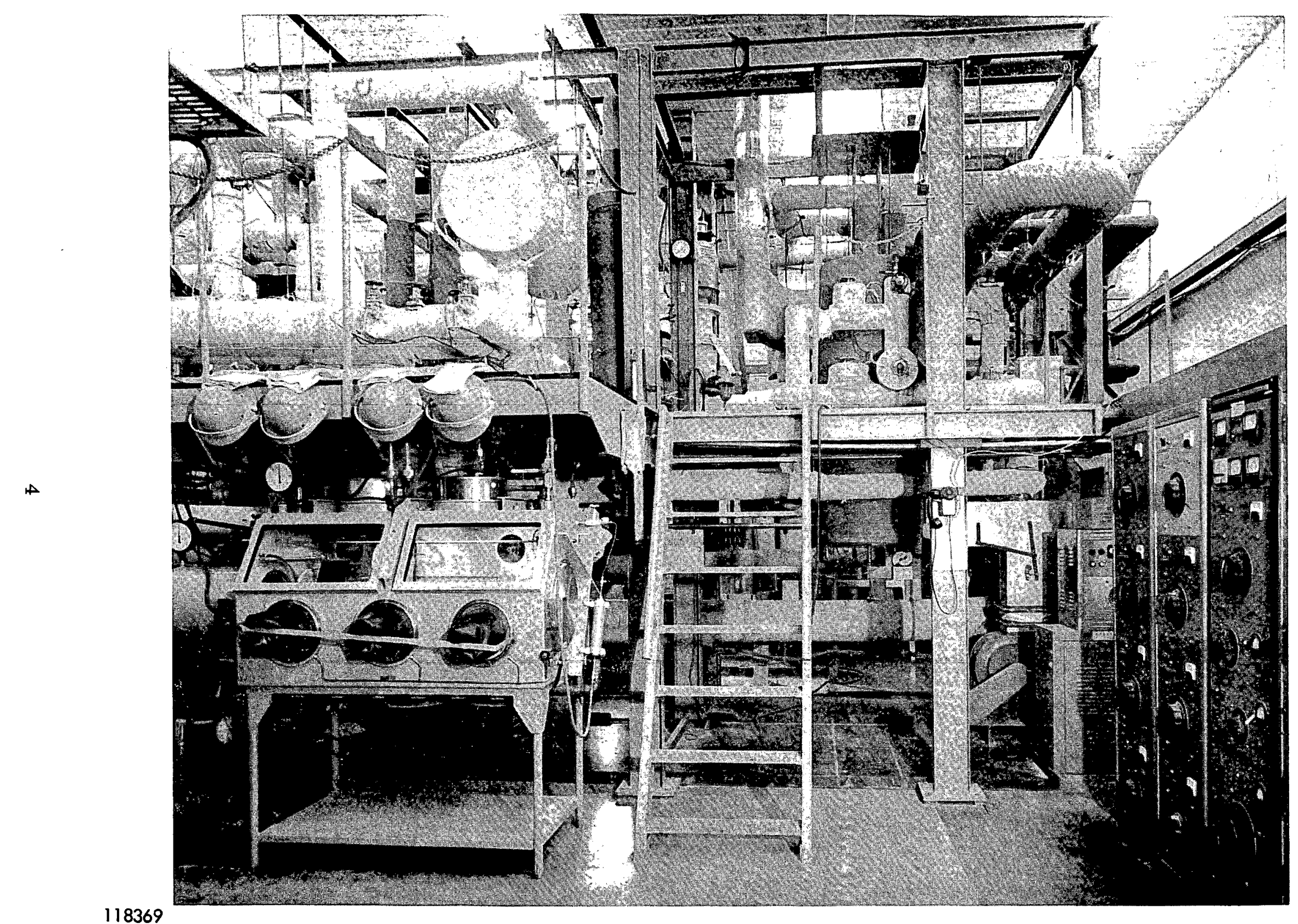

118369

FIG. 2 SODIUM TECHNOLOGY TEST LOOP 


\section{SECTION I}

IMPURITY MONITORING DEVICES 


\section{A - RHOMETER EVALUATIONS}

The objective of this job is the development of an in-line impurity monitoring instrument for detecting, monitoring, and controlling impurities in high-temperature sodium.

\section{Development Program}

APDA has conducted a preliminary evaluation of an improved automatically temperature-compensated version of the Blake-type Mark I Rhometer.* Concurrently, response of the Mark I Rhometer to sodium impurities such as sodium monoxide, sodium hydride, water, carbon monoxide, and carbon dioxide as well as the effect of gas bubbles, sodium flow rate, and gamma radiation on meter output, was established.

The original Mark I Rhometer was equipped with manual temperature compensation in the range of $400 \mathrm{~F}$ to $600 \mathrm{~F}$. It soon became apparent that if the Rhometer were to become a useful instrument for monitoring impurities in the primary and secondary systems of liquid-metal-cooled fast breeders, not only should the temperature compensation range be broadened but such compensation should be automatic.

In 1965 when the development program for an automatic temperature compensator was initiated, the state of the art for electronic components such as signal conditioners, operation amplifiers, diode function generators, zener diodes, and integrated circuits was such that the prospects for an all-electronic compensator were promising, and this course was pursued (see Figure $3)$.

The APDA prototype Rhometer output exhibits a short-term ( 24 hour), nonaccumulative, low-frequency oscillation of $0.01 \% \mathrm{R}( \pm 2.5 \mathrm{ppm}$ oxygen), a long-term band width of $\pm 0.04 \% \mathrm{R}( \pm 10 \mathrm{ppm}$ oxygen) and a high-frequency noise level of $\pm 0.005 \% R(1.3 \mathrm{ppm}$ oxygen). To achieve these conditions, it was necessary to extensively modify the control circuitry, to construct a special power supply, to house the sensing element (toroid) in an ambienttemperature-controlled enclosure, and to sense the sodium temperature at the toroid by means of a resistance temperature detector (RTD) probe.

All components of the APDA prototype have thus far exhibited very good maintenance-free histories. The three toroid transformers which were part of the three Mark I Rhometers procured by APDA, one of which was used

* An improved version of this Rhometer (Mark II) is commercially available from English Electric Company, Cambridge Road, Whetstone, England. 
in the APDA prototype, have operated without attention for over 30,000 hours; the function generator, power supply, and control circuitry have operated continuously for a period of one year; the RTD, for 7 months.

By taking advantage of recent advances in the state of the art in electronic components which comprise the subsystems of the prototype Rhometer, a long-term stability and repeatability of $\pm 0.005 \% \mathrm{R}$ resistivity $( \pm 1.3 \mathrm{ppm}$ oxygen) with a sensitivity of $\pm 0.002 \% \mathrm{R}( \pm \overline{0} .5 \mathrm{ppm}$ oxygen) appears to be an attainable goal for a commercial Rhometer.

Preliminary gamma radiation exposure tests (a 28 -curie iridium-192 source placed just outside the metal enclosure of the toroid assembly for 5 minutes) showed that Rhometer output was unaffected by such radiation.

In parallel with the development of the prototype automatically temperature-compensated Rhometer, an extensive program was conducted at APDA to determine the response coefficients of the Rhometer to sodium impurities. This work progressed through three phases of evaluation (1) cold trap injections using the plugging temperature and solubility curves to establish concentration changes, (2) specific impurity injections $\left(\mathrm{H}_{2} \mathrm{O}, \mathrm{Na}_{2} \mathrm{O}\right.$, $\mathrm{NaOH}, \mathrm{NaH}, \mathrm{CO}_{2}$ ) using material balances to determine the quantity of material injected, and (3) specific impurity injection ( $\mathrm{NaH}, \mathrm{Na}_{2} \mathrm{O}, \mathrm{NaOH}$ ) using chemical analysis of sodium samples to establish concentration changes. The latter technique was deemed to be the most accurate. For example, by thorough chemical analysis, Rhometer response coefficients were established for $\mathrm{Na}_{2} \mathrm{O}$ and $\mathrm{NaH}$. The response of the Rhometer to $\mathrm{NaOH}$ was then accurately predicted by assuming that the $\mathrm{NaOH}$ was completely converted to $\mathrm{Na}_{2} \mathrm{O}$ and $\mathrm{NaH}$ and that each of these species contributed independently to the resistivity change of sodium.

Not only does the Rhometer respond to small changes in the sodium resistivity due to dissolved impurities as mentioned above (see Figures 4 and 5), but it also responds to changes in sodium resistivity caused by bubbles of insoluble gases and by particles of insoluble solids, as indicated by a significant increase in the noise level of the output signal as the gas and particulates pass through the Rhometer toroid.

\section{Conclusions}

Although the Rhometer does not discriminate among types of dissolved impurities nor among types of particulate matter, it is a reliable instrument for continuously monitoring sodium impurities to indicate deviations from normal operating conditions. It is not affected by radiation; moreover, the stainless steel toroid is the only component of the instrument in contact with the sodium. The capability of on-line calibration of the response of the Rhometer by means of inducing a step change in resistivity of the toroid (the cutwire technique), coupled with its versatility and reliability, leads to the 
conclusion that the Rhometer is an instrument which could be commercially developed as a plant instrument for both primary and secondary sodium systems.

\section{Documentation}

This work is documented in the APDA quarterly progress reports; in APDA-149, "Evaluation of the Blake Sodium Resistivity Meter"; in APDA163, "Operation of the Sodium Technology Loop for Contamination Meter Evaluations"; in a paper, "Impurity Monitoring in a Large Sodium Test Loop," given at the Conference on Sodium Technology and Large Fast Reactor Design at Argonne, Illinois (reported in ANL-7520, pp 235-237), November 7-9, 1968; and in APDA-247, "Design, Development, and Testing of a TemperatureCompensated Rhometer for Monitoring Impurities in Sodium." 


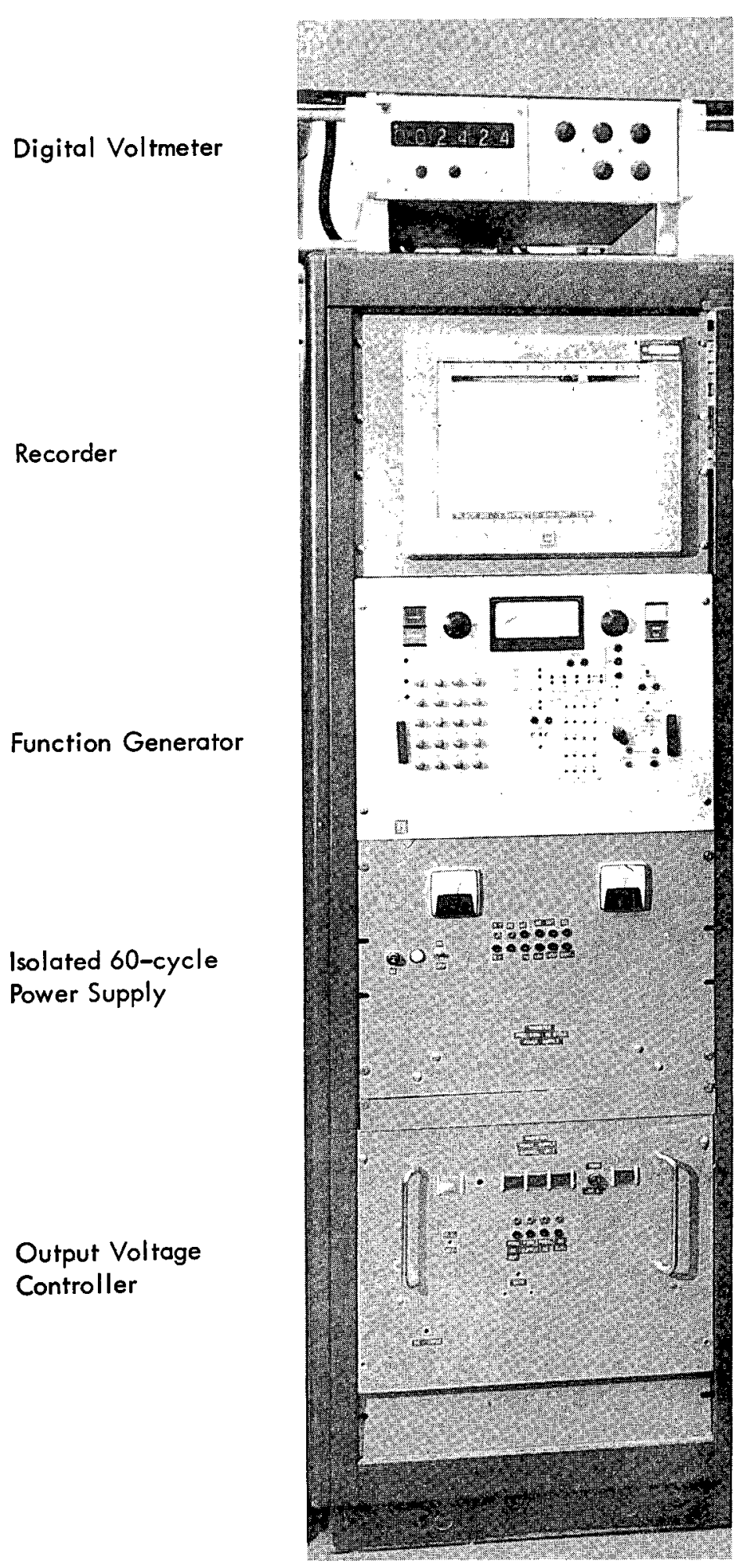



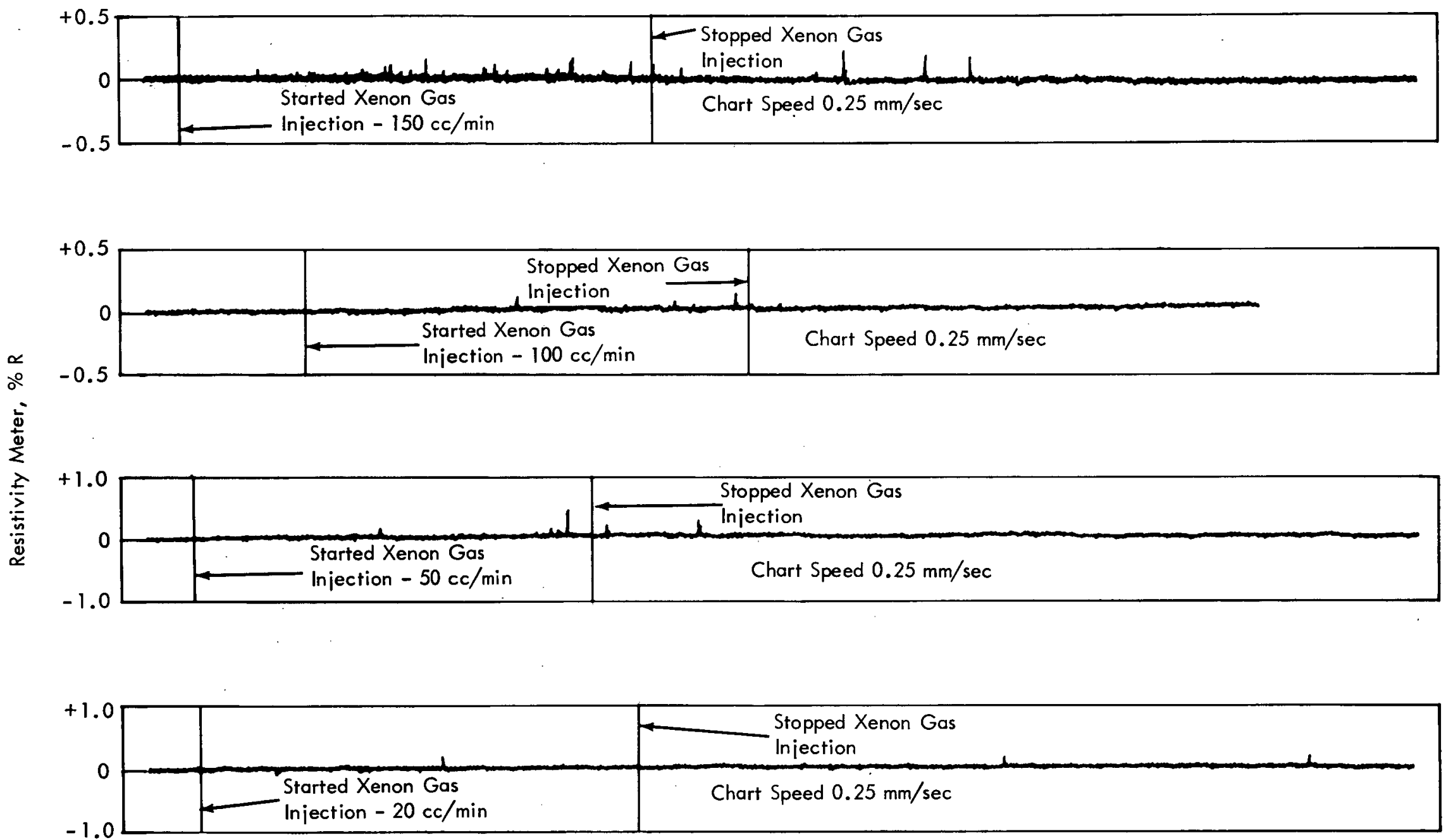

Xenon Gas Injection into

Sodium Conditions=200 GPM@570 F

Pump Discharge

Resistivity Decade $=104.449 \%$ R

Cold Trap and Hot Trap Isolated 


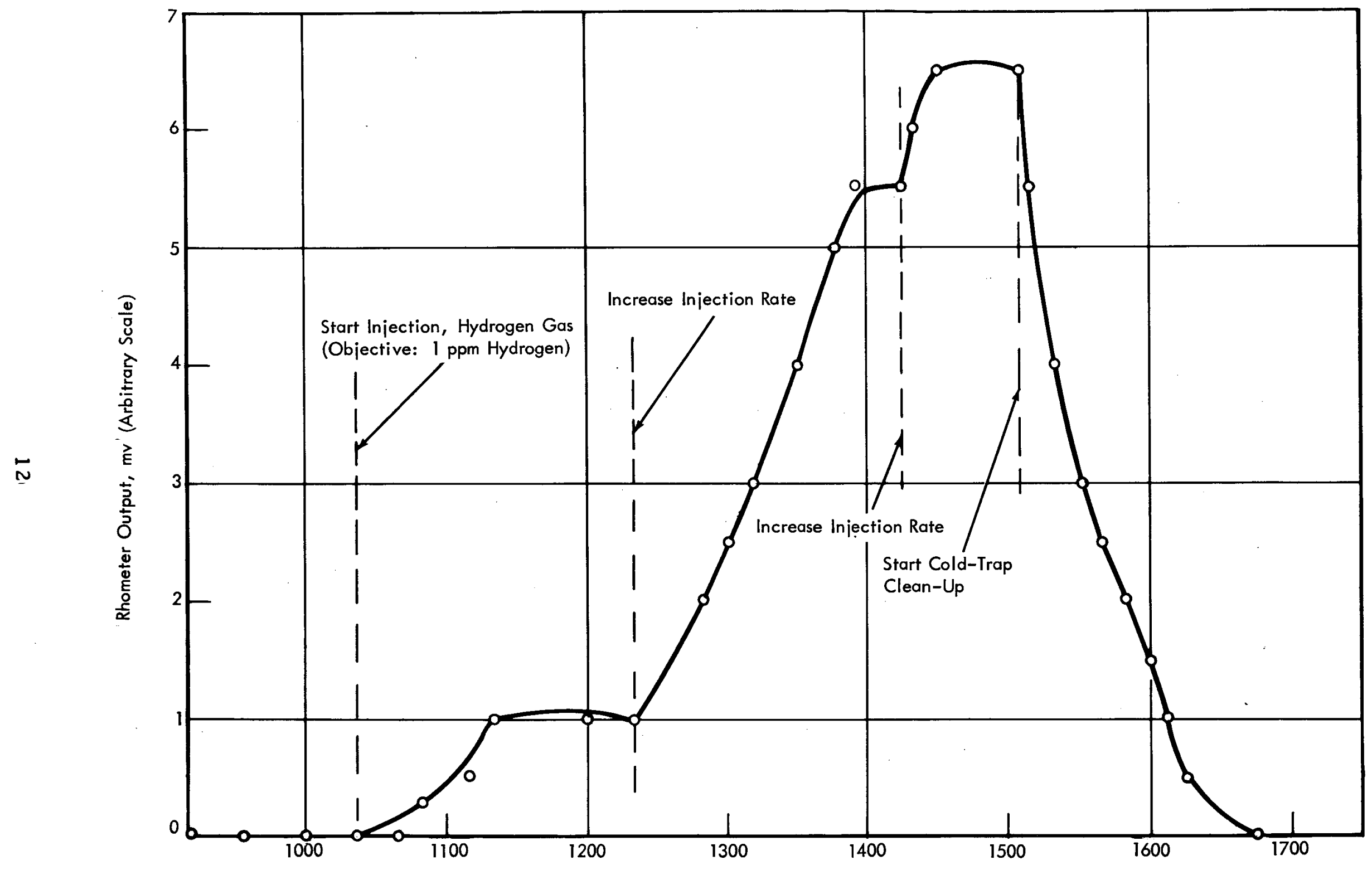

FIG. 5 RESPONSE OF AUTOMATIC TEMPERATURE-COMPENSATED PROTOTYPE RHOMETER TO INJECTIONS OF HYDROGEN GAS IN SODIUM 


\section{B - EVALUATION OF UNC OXYGEN METERS}

The scope of this work is the in-sodium evaluation of the oxygen meters (electrochemical cells) developed by United Nuclear Corporation (UNC) for the purpose of detecting oxygen activity in the sodium. The sensitivity of the meter, its accuracy, response time, and drift were studied, along with the effects of sodium and ambient temperature and gamma radiation on meter performance. In an effort to improve the instrument's performance, the variables causing operating problems were identified.

\section{Test Program}

Since 1965 twelve of the UNC meters have been evaluated in the APDA Sodium Technology Loop. The evaluation included studies of (1) the meter response to injections of impurities such as sodium monoxide, sodium hydride, and sodium hydroxide, (2) sodium and ambient temperature coefficients, and (3) the effects of gamma radiation on the meter's performance.

\section{a. Response to Impurities}

To evaluate oxygen meter response to impurities, injections of sodium monoxide, sodium hydride, and sodium hydroxide were made to the Sodium Technology Loop with the sodium maintained at $600 \mathrm{~F} \pm 5 \mathrm{~F}$. A typical oxygen meter response to a sodium monoxide injection is presented in Figure 6. The conclusions drawn from these evaluations are (1) that the meters respond to concentration changes in sodium monoxide in a quantitative and reproducible manner, (2) that the calibration constant varies from meter to meter, (3) the time response increases with insodium service, and (4) the meters respond to sodium hydroxide injections in sodium at $600 \mathrm{~F}$, although response to sodium hydride injections is inconclusive based on data obtained in this test program.

\section{b. Sodium and Ambient Temperature Coefficients}

During these tests, the sodium and ambient temperature coefficients of the oxygen meters were determined in an effort to remove the effects of temperature fluctuations from the output of the instruments. It was found that the sodium temperature coefficient of the meters varied from $0.56 \mathrm{mv} / \mathrm{F}$ to $0.04 \mathrm{mv} / \mathrm{F}$, indicating that in sodium systems having temperature fluctuations at a given meter, the temperature coefficient for that meter must be known in order to correctly interpret the meaning of meter output. 
The ambient temperature response factors of the oxygen meters were obtained at two oxygen concentrations (10 and $41 \mathrm{ppm}$ ) and with the meters mounted in boxes having a controlled environment ranging from 66 to $113 \mathrm{~F}$. From these tests it was determined that the ambient temperature response of the meters was -1.16 to $0.0 \mathrm{mv} / \mathrm{F}$ and that the oxygen concentration did not significantly affect the ambient temperature coefficient.

\section{c. Gamma Radiation}

In an effort to determine the response to radioactivity, four meters installed in the Sodium Technology Loop were subjected to radiation from a 73-curie iridium-192 source and a 12-curie cobalt-60 source. Gamma radiation caused response changes from 0 to $50 \mathrm{mv}$, depending on the meter.

\section{d. Improvement of Readout}

Due to the excessive zero drift incurred on the tube-type electrometers originally installed to continuously monitor the oxygen meters, a decision was made in April 1968 to obtain a more stable unit. The unit, Keithley Model 602, is a battery-operated solid-state amplifier utilizing a field effect transistor as the input stage. The input resistance is as high as the tube-type units $\left(<10^{14} \mathrm{ohms}\right)$; the zero drift specification is approximately an order of magnitude better than the tube-type unit.

The unit was tested and found to operate well within its drift specification of $1 \mathrm{mv} /$ day after a 30-minute warmup, after which it was installed to monitor oxygen meter No. 4 in August 1968. Since that time it has continued to operate as specified, i. e., within $\pm 0.3 \mathrm{mv}$ of zero. It is concluded that the Keithley Model 602 solid-state electrometer is entirely adequate for continuously monitoring the oxygen meters.

\section{e. Cell Life at $900 \mathrm{~F}$}

The life of oxygen meter 3 (UNC TPE-1/216 - the only meter tested above $600 \mathrm{~F}$ ) in $900 \mathrm{~F}$ sodium was 18 days, following a successful operating life of 18 months in $600 \mathrm{~F}$ sodium.

\section{Conclusions}

Further development is required to produce oxygen meters with meter characteristics in a narrower band than those evaluated by APDA. Without such development, each meter must be individually calibrated for its response to oxygen, sodium temperature, ambient temperature, and gamma radiation in order to interpret the meaning of its output. 


\section{Documentation}

This work is reported in a paper, "Impurity Monitoring in a Large Sodium Test Loop, " presented at the International Conference on Sodium Technology and Large Fast Reactor Design, Argonne National Laboratory, November 7-9, 1968, and in APDA quarterly progress reports, particularly APDA-242. A topical report, "Experience with UNC Oxygen Meters in APDA Sodium Technology Loop," APDA-245, was published at the close of the program. 


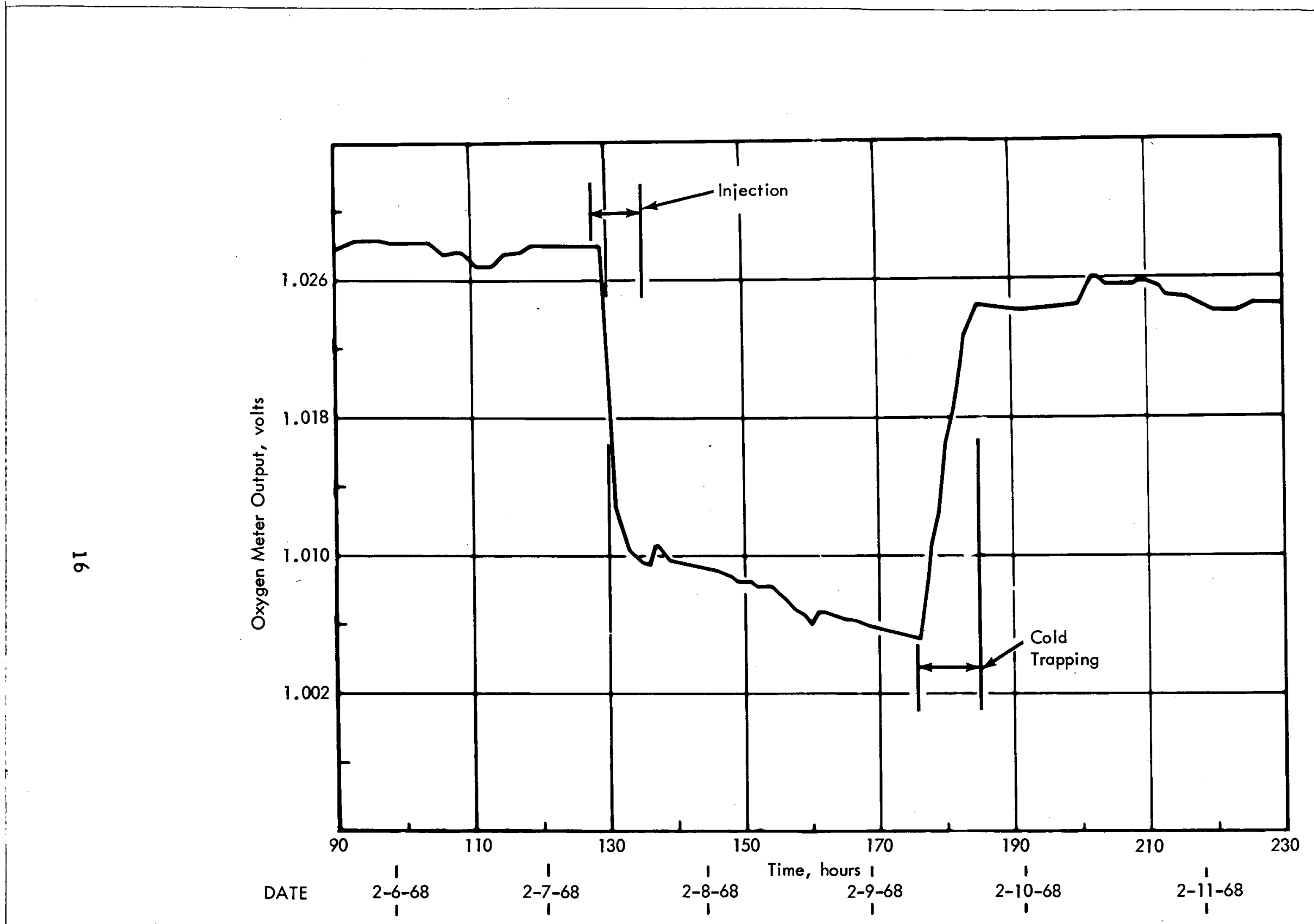

143470

Fig. 6 tYPICAL RESPONSE OF OXYGEN METER tO INJECTION OF 16 PPM OXYGEN AS SODIUM MONOXIDE 


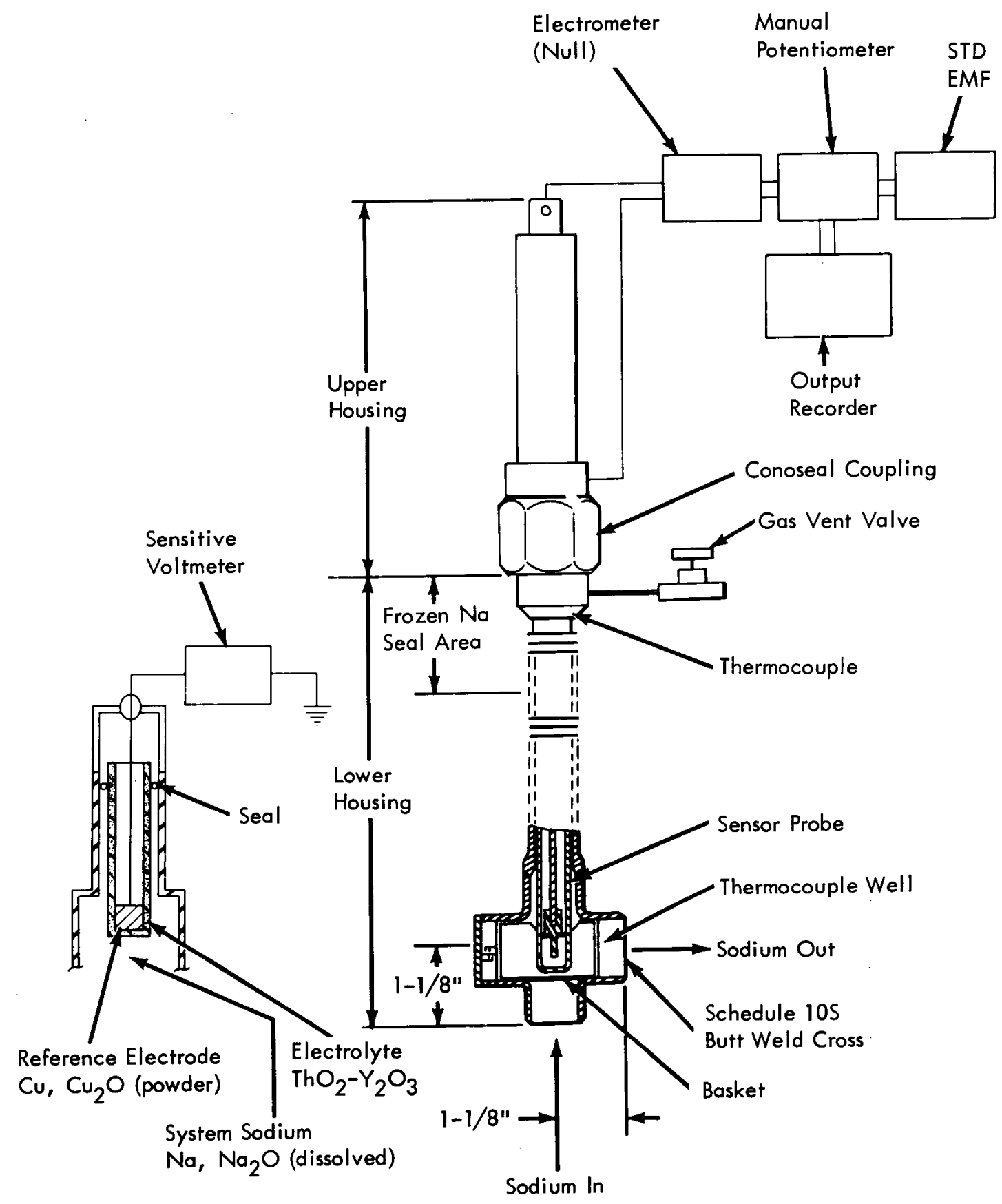


•

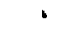

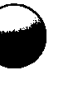
•

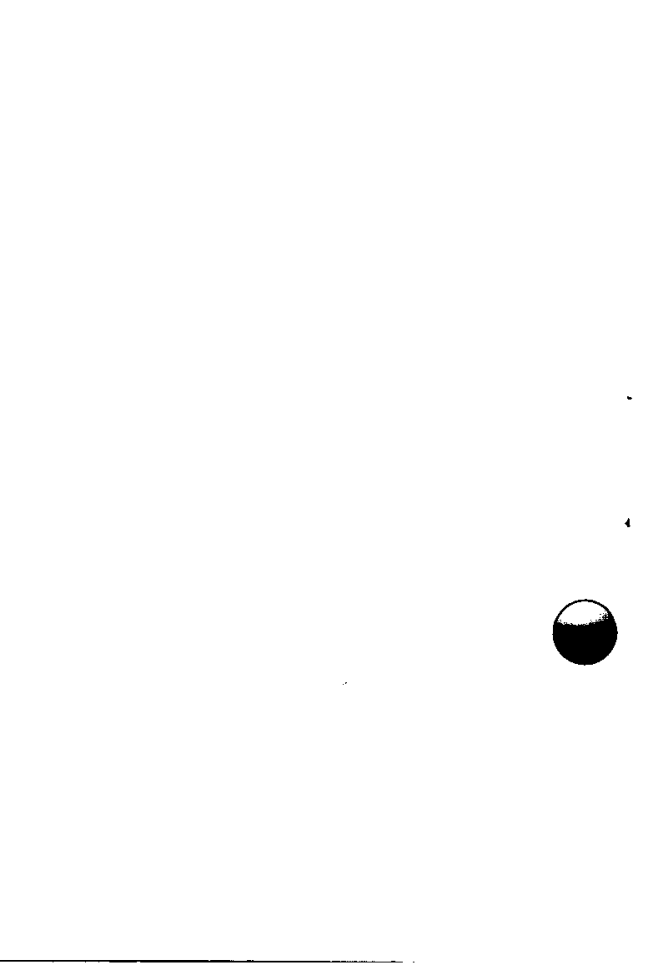




\section{C - HYDROGEN DETECTOR}

The objective of this job was to develop an in-line detector for monitoring hydrogen in sodium. The development effort proceeded in two phases:

- Phase I - A laboratory feasibility study

- Phase II - Loop evaluation of a palladium-plated sensor coil

\section{Test Program}

a. Phase I - Laboratory Feasibility Study

As a result of this study, the feasibility and design considerations which apply to a hydrogen detector based on the diffusion of hydrogen through a nickel-palladium membrane followed by the catalytic oxidation of the hydrogen on the palladium surface to water and its subsequent detection by a moisture monitor were determined. Three types of sensor coils were evaluated: a palladium-plated nickel coil, a nickel-plated palladium coil, and a coil formed from codrawn nickel and palladium tubing. The sensors were evaluated by injecting such hydrogen-containing species as hydrogen gas, sodium hydroxide, sodium hydride, and water into a container of sodium; they were responsive to each of the se forms of hydrogen-containing compounds. It was demonstrated that the experimental detector would respond to a change of hydrogen concentration in sodium as low as 2 parts per billion. The response time required to detect a step change in hydrogen concentration in the experimental equipment was as low as 15 seconds. The hydrogen detector coil is shown in Figure 8.

\section{b. Phase II - Loop Evaluation}

A palladium-plated sensor coil was installed in the APDA Sodium Technology Loop to evaluate this type of hydrogen detector in a dynamic sodium system. The evaluation consisted of (1) a determination of the response of the detector to injections of hydrogen-containing compounds ( $\mathrm{NaH}, \mathrm{H}_{2}$ gas, and $\mathrm{H}_{2} \mathrm{O}$ ) and subsequent cold-trapping, (2) the effect of sodium flow rate, (3) the effect of sweep gas flow rate, (4) the effect of loop temperature, (5) the effect of sensor temperature, (6) response time, and (7) suitability of the moisture-sensing equipment.

Response to Hydrogen Impurities - The detector responded to each of the types of hydrogen impurities mentioned above. The injection of sodium hydride equivalent to an increase of 1 ppm hydrogen in the loop sodium caused the readout to increase from a base level of $8 \mathrm{ppm} \mathrm{H}_{2} \mathrm{O}$ to 
$105 \mathrm{ppm} \mathrm{H}_{2} \mathrm{O}$. The response to water injections equivalent to an increase of $0.75 \mathrm{ppm}$ hydrogen in the loop sodium demonstrated the capability of the hydrogen detector to detect water leaks in either a cover gas space or below sodium. The detector output increased to $30 \mathrm{ppm} \mathrm{H}_{2} \mathrm{O}$ from a base level of about $1 \mathrm{ppm} \mathrm{H}_{2} \mathrm{O}$ for a water injection above the sodium level in the APDA Sodium Technology Loop surge tank (see Figure 9). Gaseous hydrogen injections accomplished by diffusing hydrogen through a nickel coil constituted the major portion of the impurity injection evaluation. Hydrogen injection ranged from $0.020 \mathrm{ppm}$ to $3.0 \mathrm{ppm}$, giving a response coefficient which ranged from 27 to $79 \mathrm{ppm} \mathrm{H}_{2} \mathrm{O}$ per ppm $\mathrm{H}_{2}$.

Effect of Sodium Flow Rate - The sodium flow rate through the sensor coil was viewed over the range of 1 to $2.5 \mathrm{gpm}$ with no effect on the hydrogen detector output.

Effect of Sweep Gas Flow Rate - A limited amount of test data indicated that the hydrogen detector output appeared to be inversely proportional to the flow rate of the sweep gas, a mixture of $5 \%$ oxygen in argon. This gas contained the oxidant for diffusing hydrogen and carried the water to the moisture detector.

Effect of Loop Temperature - Sufficient data were not obtained to make a definitive statement with regard to this variable. No significant differences were obtained when injections of hydrogen were made at previous loop temperatures. On the other hand, in some cases changing the loop temperature at a given loop hydrogen concentration produced changes in the hydrogen meter readout and in other cases it did not.

Effect of Sensor Temperature - The effect of the sensor temperature was studied over the range of 800-900 F. The effect of sensor temperature was in fair agreement with that predicted by the activation energy for diffusion.

Response Time - It was not possible to make an accurate measure of the response time of the instrument. The overall system response time was approximately 5 minutes. Of this 5 minutes, 2 minutes are accounted for in the hydrogen injection, 2 minutes for the sodium transport time, and $1 / 2$ minute in the sweep gas system transport time. It is estimated from these data that the response time of the APDA hydrogen detector is less than $1 / 2$ minute.

Panametric Hygrometers - APDA experience with the Panametric hygrometer has demonstrated the need for a more precise calibration of the individual moisture-sensing probe than is available from the manufacturer. Probes now on hand appear to differ in calibration by a factor of 3 . 


\section{Conclusions}

The APDA hydrogen detector has been demonstrated to be a candidate instrument in the LMFBR program for monitoring hydrogen in sodium and as a leak detector for monitoring leaks in steam generators.

3. Documentation

Feasibility Study of In-Line Detector for Hydrogen in Sodium APDA-222, 1968.

Evaluation of an In-Line Hydrogen Detector in the APDA Sodium Technology Loop - APDA-252. 


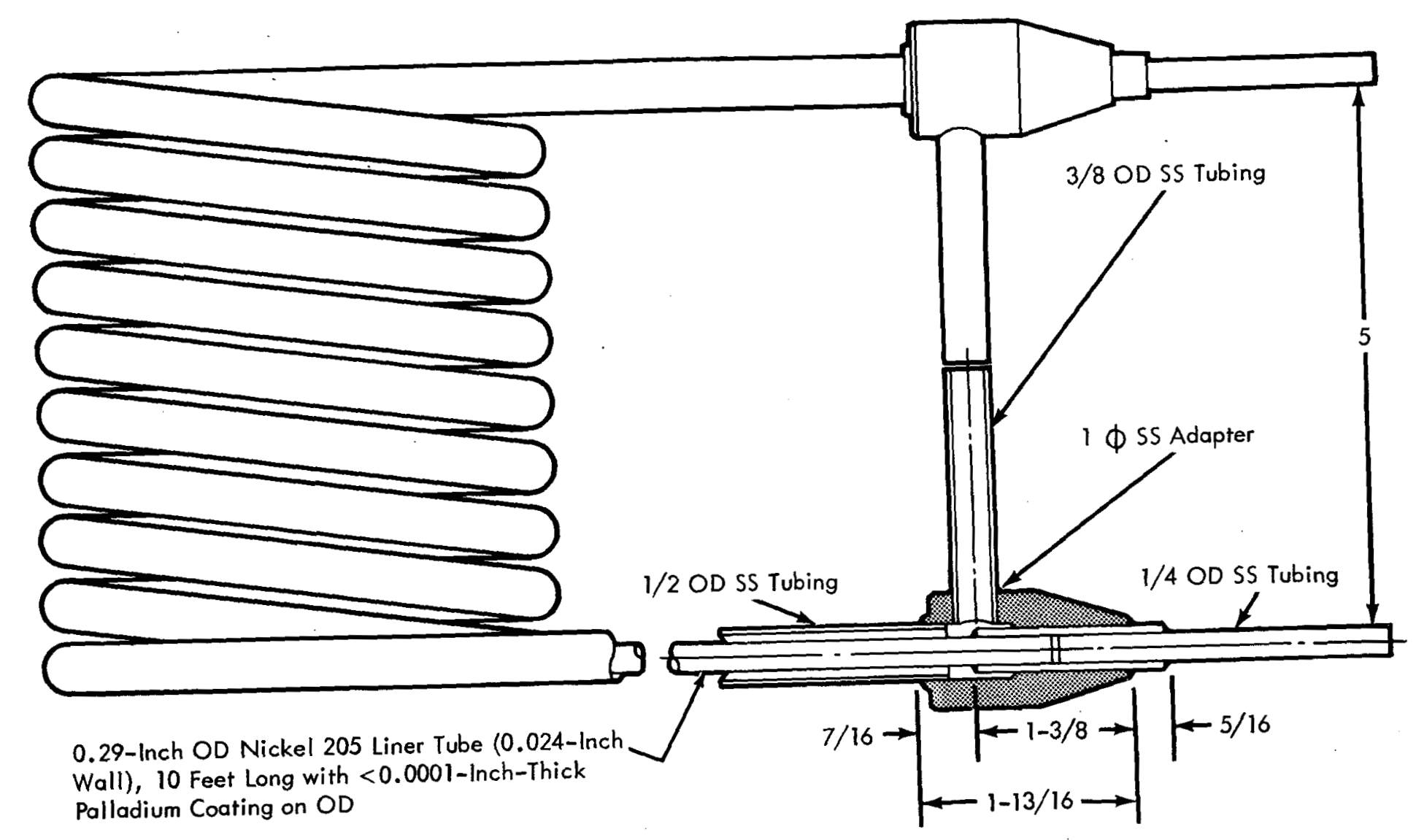

All Dimensions in Inches

FIG. 8 APDA HYOROGEN DETECTOR COIL 


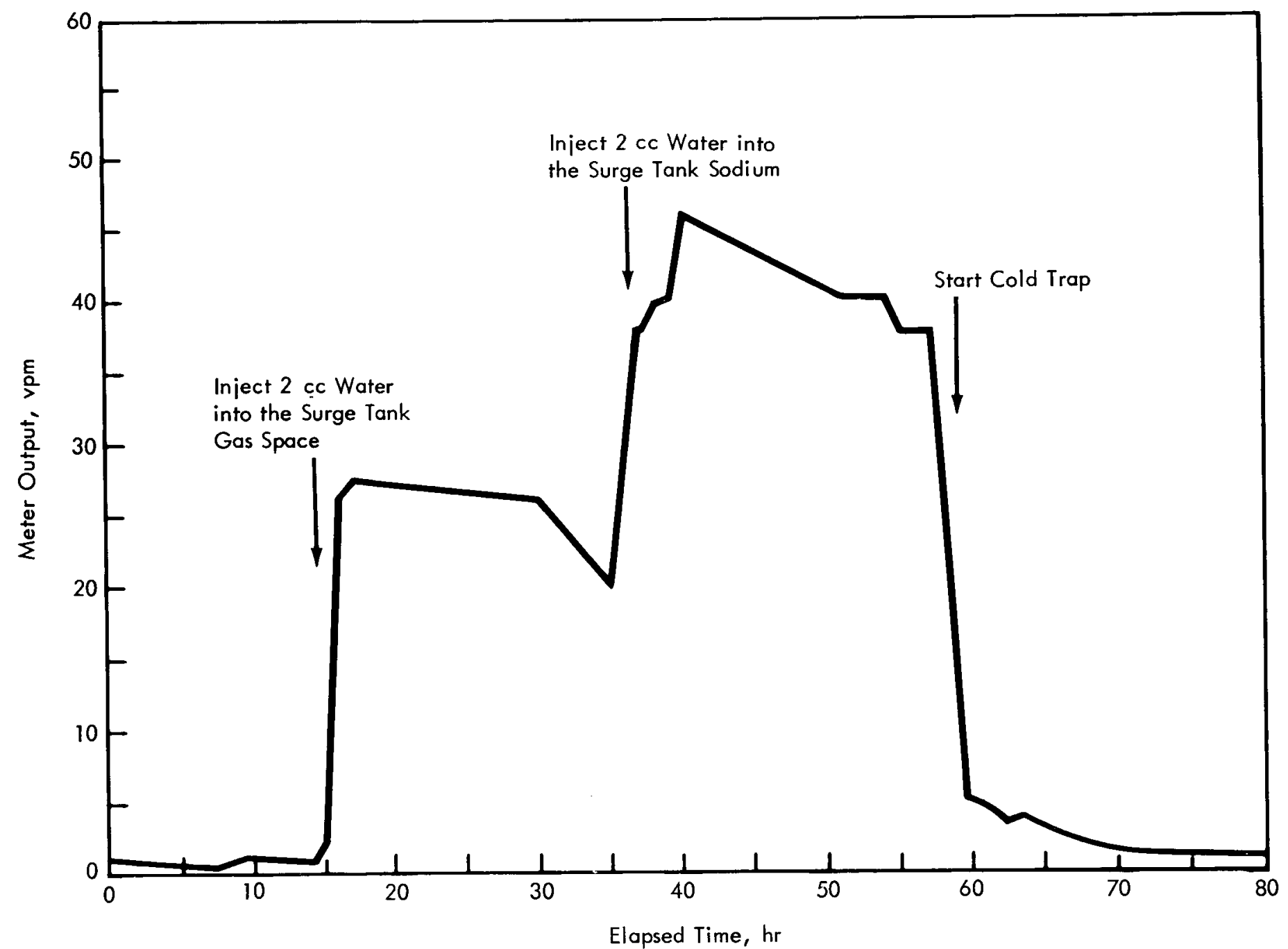


。

•

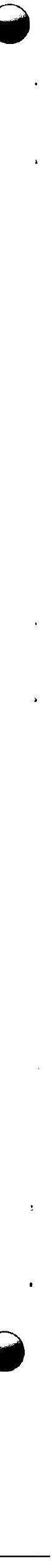




\section{D - PLUGGING METER}

The APDA intermittent plugging meter was used primarily as a guide in the operation of the Sodium Technology Loop to indicate when purity levels had changed significantly from cold-trapped conditions and to indicate when to terminate clean-up operations. However, during the evaluation of other impurity monitoring devices such as the Rhometer, UNC oxygen meter, and the APDA hydrogen detector, the behavior of the plugging meter was observed and analyzed.

\section{Plugging Meter Installation}

The instrument used for this study is a variable-orifice, air-cooled plugging meter installed in a side loop of the 4-inch loop. The unit consists of a special $1 / 2$-inch bellows-seal globe valve with a seat ground to a 15-degree angle for close control of clearance. A special fine thread on the stem and position indicator permits clearance settings to a tolerance of $1 \mathrm{mil}$. The temperature ramp is controlled by controlling forced air flow past the $1 / 2$-inch finned sodium line by a hand-operated slide valve (see APDA-163 for installation diagram).

\section{Results and Discussion}

Initial evaluation of this meter in 1964 (see APDA-163) produced plugs from 213 to $670 \mathrm{~F}$ under tests with reproducibility to $\pm 5 \mathrm{~F}$ and fur nished consistent values for sodium hydride contamination. This order of reproducibility was demonstrated in more recent tests described in a paper, "Impurity Monitoring in a Large Sodium Test Loop," ANL-7520, Part I, pp 233-253. Plugging temperatures obtained under sodium monoxide contamination agreed with accepted solubility data when loop oxygen concentrations were calculated by means of material balances. Sodium hydroxide contamination plugging temperatures were higher than anticipated. Later tests, based on chemical analysis of sodium samples (ANL-7520, p 244), showed that the plugging temperature increases resulting from the injection of sodium hydroxide or sodium hydride to cold-trapped sodium indicated only the increase in the sodium hydride concentration of the sodium.

A common practice is to use plugging temperatures with data on sodium monoxide solubility in sodium to infer the amount of oxygen impurity in sodium. Experience at APDA has shown, however, that this practice may lead to erroneous conclusions. For example, in a 12-day test span with the loop sodium at $600 \mathrm{~F}$, the plugging temperature increased steadily from $264 \mathrm{~F}$ to $304 \mathrm{~F}$, whereas sampling and analysis results 
indicated essentially the same oxygen concentration $(11.3 \pm 1.8 \mathrm{ppm})$ over the same period.

The APDA Sodium Technology Loop is usually operated at $600 \mathrm{~F}$. At this temperature, the loop is easily cleaned up to a plugging temperature of $225 \mathrm{~F}$; upon termination of the cold trapping operation, the plugging temperature remains fairly constant. However, at loop temperatures of 700 to $900 \mathrm{~F}$, under conditions of relatively clean sodium $(<10 \mathrm{ppm}$ oxygen and $<4$ ppm total hydrogen), the plugging temperature increased without a corresponding change in the measured oxygen or hydrogen concentration. The maximum plugging temperature observed was $620 \mathrm{~F}$ when the loop temperature was $900 \mathrm{~F}$ (see APDA-242).

Efforts to reduce the plugging temperature by cold-trapping or hottrapping were only successful during the cold-or hot-trapping operation. Within 24 hours the plugging temperature had increased to over $500 \mathrm{~F}$. By lowering the loop temperature to $600 \mathrm{~F}$, the plugging temperature decreased and in 6 days reduced to $240 \mathrm{~F}$. These test results suggest that the high plugging temperatures are caused by chemical species other than hydrogen or oxygen.

\section{Conclusions}

- The plugging meter is a reliable instrument for indicating the temperature at which impurity saturation occurs

- Plugging temperatures near the freeze point of sodium are a reliable indication that the sodium has reached a purity that is usually less than $10 \mathrm{ppm}$ oxygen or $2 \mathrm{ppm}$ total hydrogen

- Inference with regard to the level of impurities in sodium when the plugging temperature is greater than $270 \mathrm{~F}$ is frequently erroneous.

\section{Documentation}

Operation of the Sodium Technology Loop for Contamination Meter Evaluations - APDA-163, March 1964.

Quarterly Technical Progress Report on AEC-sponsored Activities, April-June 1969 - APDA-242. 


\section{SECTION II}

EVALUATION OF MECHANICAL PURIFICATION CONCEPTS 


\section{A - SODIUM CENTRIFUGE}

The scope of this program is the investigation of mechanical purification devices capable of removing very small particles from the sodium systems of LMFBRs. The work includes a review of the performance characteristics of standard devices as well as novel concepts, and determination of the optimum combination of methods for effective and economic particle removal.

\section{Test Program}

A functional specification for a high-speed sodium centrifuge was prepared and submitted to several manufacturers, all of whom declined to bid. Subsequently, a conventional centrifuge was selected for adaptation to the functional specification; and, in consultation with Sharples Division of Pennsalt Chemicals Corporation, APDA finalized the design of a sodium centrifuge featuring a bottom-fed, top-discharge bowl suspended from a spindle driven at speeds up to $50,000 \mathrm{rpm}$ by a turbine producing a centrifugal force of $62,000 \mathrm{~g}$ at the bowl wall (see Figure 10). The bowl is enclosed in an insulated, heated housing and all components except the turbine drive are contained in an argon-filled glove box to maintain an inert atmosphere over the free surface of the sodium in the bowl and the collecting chamber. The centrifuge and piping components are arranged to facilitate removal of the centrifuge bowl for examination of its contents. Safety devices were installed on the centrifuge and piping system to shut down the turbine drive, electromagnetic pump, and sodium loop valves in the event of mechanical or control problems.

A program of tests was initiated to determine the dynamic characteristics of the unit, to become familiar with its operation prior to modification, and to individually test the modified components of the centrifuge. Concurrently, work was done on a design concept for installation of the centrifuge in the Sodium Technology Loop (see Figure 11). Environmental control around the centrifuge was investigated from the standpoint of avoiding contamination of the sodium being processed and in terms of manipulation of the equipment required.

\section{a. Developmental Tests}

The final design contrifuge was assembled in its spherical glove box and a series of tests was performed in water to demonstrate the unit's readiness for sodium operation. In this series of tests, only minor problems were encountered, and the glove box containing the centrifuge was connected to the APDA Sodium Technology Loop. The system was operated 
at $350 \mathrm{~F}$ in an argon atmosphere without sodium flow. The centrifuge was operated at 50,000 rpm for 15 hours, during which time no unusual events occurred and the rotational speed remained relatively constant.

\section{b. Initial Operation in Sodium}

The sodium line valve was opened and a flow of $350 \mathrm{~F}$ sodium was established at $1 / 4 \mathrm{gpm}$. The centrifuge was then operated for 24 hours, during which period the only problem was a very slow leak of sodium from the housing. The sodium flow was shut off; the centrifuge was allowed to cool to room temperature and was then disassembled, placed in a plastic bag, and moved to a very pure atmosphere glove box in the chemistry laboratory for analysis of the problem.

Examination of the bowl contents revealed a higher concentration of impurities adjacent to the bowl wall, and it was decided to core out the purer sodium and leave an annulus of approximately 0.010 inch of impuritycontaining sodium on the lower $1-1 / 2$ inch of the bowl. This section of the bowl was sent to Battelle Memorial Institute for detailed analysis of particle size, elemental composition, and identification of compounds through optical and scanning microscopy, electron microprobe, optical emission, spectroscopy, and $\mathrm{X}$-ray diffraction analysis. These analyses revealed an adherent film containing no discernible particles and an area containing 1 to 3 micron particles. X-ray diffraction identified carbon and silicon dioxide as being present in the sample. No other elements or compounds were present in sufficient quantity that diffraction patterns could be seen. Optical emission spectrographic analysis revealed silicon to be the largest constituent detectable by this means. Carbon analysis revealed a $13.6 \%$ content by weight.

\section{c. Long-Term Operation}

Following the initial operation, a test was conducted to demonstrate the ability of the centrifuge to operate over an extended period of time. The operating conditions were 50,000 rpm with a sodium flow rate of $1 / 4 \mathrm{gpm}$ and sodium temperature at $480 \mathrm{~F}$. At the end of a 93-hour period, the sodium flow was shut off, the centrifuge slowed to $4000 \mathrm{rpm}$ with the heat turned off to allow the sodium remaining in the bowl to solidify. The total period of uninterrupted rotation was 120 hours. No serious damage was found when the unit was disassembled and examined.

\section{Conclusions and Recommendations}

Based on the demonstrated successful operation of the centrifuge, two avenues for further development are apparent: one is to make several improvements to the design of the present unit and test a number of the 
improved units; the second is to design a larger improved model for testing as a prototype in-line sodium purification device for reactor systems.

\section{Documentation}

Design, Development, and Evaluation of a Continuous Flow Sodium Centrifuge - APDA-243, December 1969. The work is also reported in the APDA quarterly progress reports. 


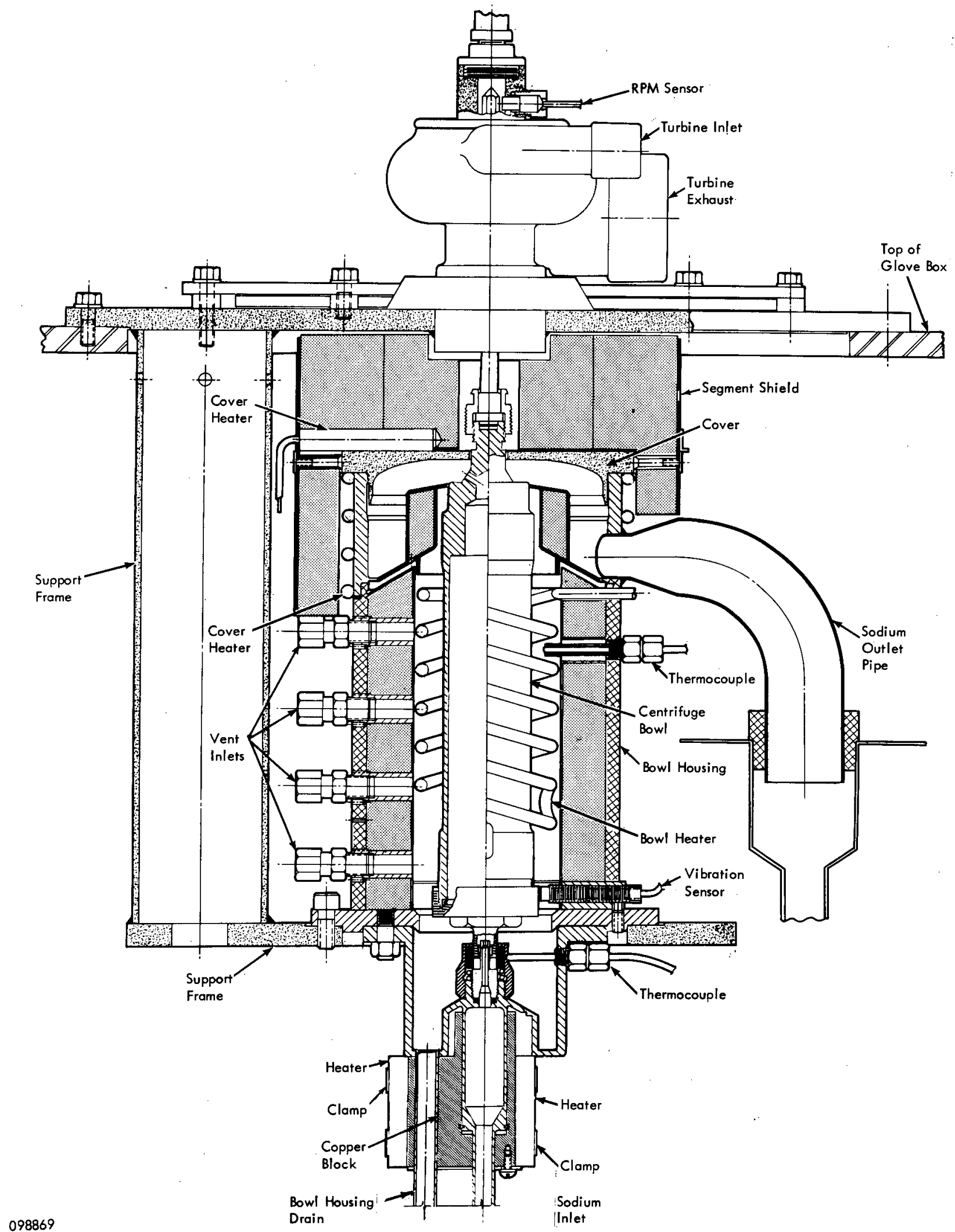

FIG. 10 CROSS SECTION OF SODIUM CENTRIFUge 


$$
\begin{aligned}
& \text { Existing Cold Trap Lines } \\
& \text { Existing Economizer Lines } \\
& \text { Sodium Supply to Centrifuge } \\
& \text { Bass Lines }
\end{aligned}
$$

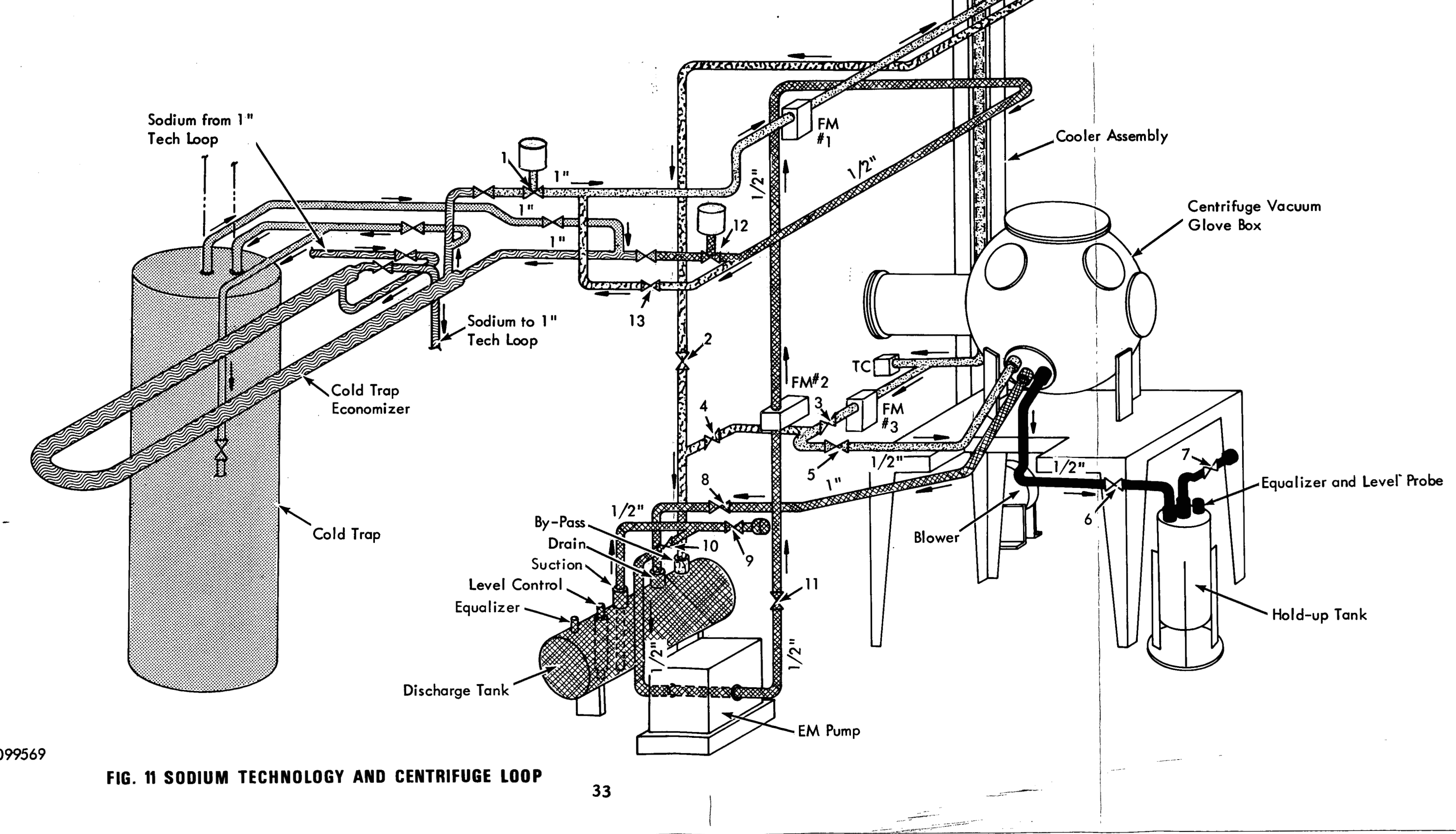




\section{B - MOVABLE BED GETTERING}

The scope of this work is the compilation of information on insoluble getter materials, the selection of candidate materials for a test program, and a program to design, build, and test model hot traps using the candidate getter materials for removing oxygen, carbon, nitrogen, or hydrogen from primary and secondary sodium during recovery or steady-state operation. The proposed process consists of eliminating impurities by introducing small spherical particles of getter materials to the system, transporting the spheres in conventional sodium plumbing by sodium flow, separating the spheres from the mainstream of the sodium, and regenerating the spheres.

\section{Test Program}

Several getter materials were examined with respect to their affinity for carbon, hydrogen, and oxygen impurities in sodium, and their regeneration characteristics and compatibility with sodium. The availability of the materials in quantities needed for testing purposes was also investigated.

The final selection for the gettering materials was zirconium and tantalum for hydrogen impurities; titanium and tantalum for oxygen; and Type 304 stainless steel for carbon. The regenerative process for hydrogen and carbon was selected, although no decision was reached regarding the process for oxygen. Particle specifications were prepared and quotations obtained indicating the average cost of the materials would be between $\$ 300$ and $\$ 400$ per pound.

Concurrently, preliminary work was done on the second phase of the program. This was concerned with the design for modifications to an existing loop which had been used in the study of a paste blanket concept for fast reactor application.

Further work on this project was precluded by reduction in the FY -68 budget. 
$\theta$

$\theta$

L 


\section{C - COLD-TRAPPING}

Cold-trapping was used exclusively as an operational cleanup device to purify the loop sodium in preparation for evaluation of such on-line impurity monitors as the Rhometer, oxygen meter, and hydrogen detector. The reference point of purity was well cold-trapped sodium, i. e. , loop sodium that had been cold-trapped until the plugging temperature was less than $215 \mathrm{~F}$. No fundamental studies of the cold-trapping operation were undertaken to provide engineering design data. The intention here is to record pertinent information obtained during the operation of the APDA cold traps.

\section{Cold Trap Installation}

There are two cold traps in the APDA sodium technology facility (shown in Figure 1), one for the 4-inch sodium loop and one for the 1 -inch loop. Both are air cooled. The 4-inch loop cold trap consists of a $30-$ gallon vertical tank with a 4 -inch downcomer inlet. Sodium exits from the downcomer near the bottom of the 30-gallon tank and flows up on the outside of the downcomer through Yorkmesh packing and then through a 5-micron-frit filter before it is discharged from the cold trap.

The 1 -inch loop cold trap consists of a 52 -gallon vertical tank which contains a shell open at the bottom and containing Yorkmesh in its interior. Sodium flows down the 3/4-inch annulus formed by the two shells to within 4 inches of the bottom, up through the Yorkmesh packing, and is then discharged from the cold trap. The technology loop inventory is about 110 gallons and both cold traps are operated at approximately 1 to $2 \mathrm{gpm}$.

\section{Conclusion}

The purification capability of both cold traps as determined by the analysis of sodium samples taken is essentially the same. When the plugging temperature is less than $215 \mathrm{~F}$, the oxygen and hydrogen concentrations, as determined by the mercury amalgamation method, are approximately $7 \mathrm{ppm}$ oxygen and $1.5 \mathrm{ppm}$ total hydrogen.

It is interesting to note that the hydrogen level for cold-trapped sodium predicted by the APDA hydrogen detector is $0.02 \mathrm{ppm}$. The discrepancy between the hydrogen concentraion as determined by the two different techniques led to the belief that there is significant blank contribution from the sampling tubes in the mercury amalgamation determi- 
nation. Some very preliminary experiments on sampling tubes free of sodium supports this conclusion.

\section{Documentation}

Quarterly Progress Report on AEC Activities (APDA-206) and "Impurity Monitoring in a Large Sodium Test Loop," a paper presented at the International Conference on Sodium Technology and Large Fast Reactor Design, held at Argonne, Illinois, November 7-9, 1968, ANL-7520, Part I, p 233. 


\section{D - HOT-TRAPPING}

The hot trap located in the APDA Sodium Technology Loop facility was used very infrequently throughout the sodium technology program conducted at APDA. There was no planned program to study conventional hot-trapping as an impurity removal process. A program was undertaken, however, to study movable bed gettering as a cleanup process for sodium (see Section II. B for a summary of this task). APDA's hot trap was used on two occasions: to study the performance of the UNC oxygen meter in hot-trapped sodium and to determine the effectiveness of hot-trapping on reducing the high plugging temperature observed whenever the loop sodium temperature was raised more than a hundred degrees above the normal operating temperature of $600 \mathrm{~F}$. A summary of these studies is presented below.

\section{Hot Trap Installation and Operation}

The location of the hot trap in the APDA Sodium Technology Loop is shown in Figure 1. It is constructed from Type 304 stainless steel Schedule 40 pipe 6 feet 8 inches long and packed with $1 / 2$-inch zirconium chips. The sodium flows downward through the zirconium bed and then through a 5-micron metallic-frit filter located at the bottom of the hot trap and exits from the hot trap through a piece of $1 / 2$-inch stainless steel tubing connected to the filter. At the normal supply rate of $1 \mathrm{gpm}$ to the hot trap, the residence time of the sodium is approximately 9 minutes. The hot trap is operated in the range of $800-1000 \mathrm{~F}$.

The best measure of the hot trap performance was obtained during a program designed to check the response of the UNC oxygen meter to hottrapped sodium. The sodium technology loop was operated isothermally at $600 \mathrm{~F}$, with the exception of the hot trap which was operated for 56 hours at $1000 \mathrm{~F}$ and then for 83 hours at $800 \mathrm{~F}$. The entire loop sodium inventory was processed through the hot trap approximately 30 times during the first hot-trapping operation and 45 times during the second hot-trapping operation.

\section{Conclusions}

As determined by the mercury amalgamation procedure, oxygen concentration was $12 \mathrm{ppm}$ before the first hot-trapping, $8 \mathrm{ppm}$ after the first hot-trapping, and $8 \mathrm{ppm}$ after the second hot-trapping; however, extrapolation of the output of a UNC oxygen meter, which had been calibrated at $12 \mathrm{ppm}$ oxygen and higher, indicated $2.3 \mathrm{ppm}$ oxygen following the first hot-trapping and $0.7 \mathrm{ppm}$ oxygen following the second hot-trapping. The hydrogen concentration (also determined by mercury amalgamation), which 
was initially $2.5 \mathrm{ppm}$ total hydrogen, dropped to $1.6 \mathrm{ppm}$ hydrogen after the first hot-trapping operation with no significant change after the second hot-trapping operation.

It appears that following the hot trap operation, the oxygen concentration was below the detectable limit of the analytical chemical method used. The best estimate of the oxygen concentration following hot-trapping is that obtained from the oxygen meter measurements.

Hot-trapping at $1000 \mathrm{~F}$ was effective in reducing the plugging temperature of $900 \mathrm{~F}$ loop sodium from $620 \mathrm{~F}$ to $265 \mathrm{~F}$ after 48 hours of operation; however, the rise in plugging temperature was very rapid after the hot trap was secured, with the plugging temperature increasing to $490 \mathrm{~F}$ in six hours. The zirconium chips in the hot trap were not examined and there is no available information as to impurities that might have been picked up by it.

\section{Documentation}

Quarterly Progress Reports on AEC-Sponsored Activities APDA-212 and APDA - 242 . 
SECTION III

PHYSICAL AND CHEMICAL

BEHAVIOR OF SODIUM IMPURITIES 
$\theta$
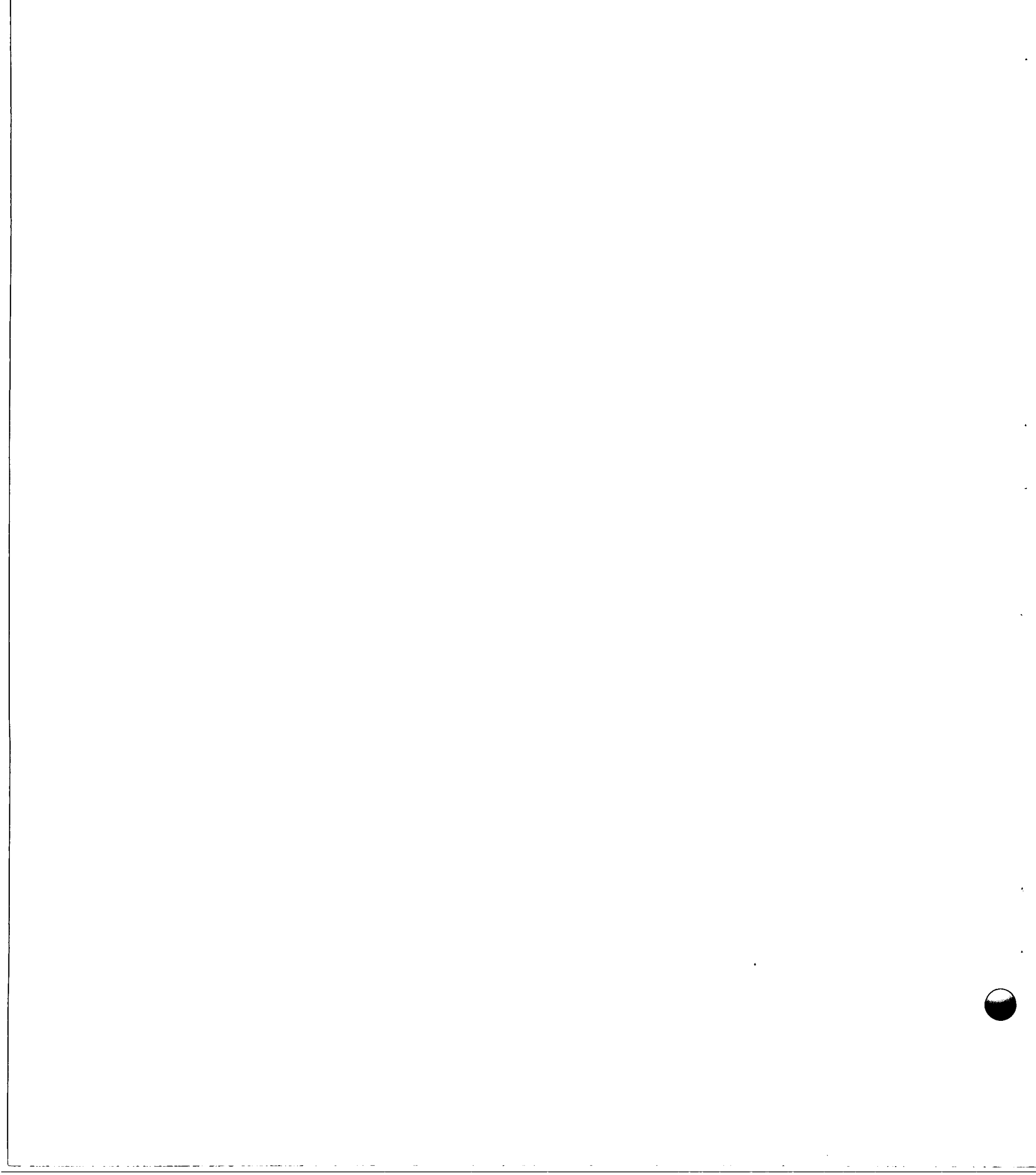


\section{A - SOLUBILITY OF HYDROGEN IN SODIUM}

This study had two basic objectives:

- To determine the solubility of hydrogen in sodium over the temperature range of 550 to $750 \mathrm{~F}$ at pressures less than $1 \mathrm{~mm}$ of mercury

- To determine the hydrogen equilibrium pressure for an unsaturated sodium system as a function of temperature, especially that region of the system containing more than 1 ppm of hydrogen in sodium.

\section{Experimental Program}

The closed-cell technique (see Figure 12) used by APDA consisted of equilibrating hydrogen gas with sodium of controlled purity contained in a thin-walled nickel capsule at isothermal conditions. Figure 13 illustrates the experimental apparatus used for system pressures greater than $1 \mathrm{~mm}$ of mercury.

\section{Conclusions}

The present data represent the best direct experimental agreement with Sievert's law reported to date and indicate that Sievert's law is most exactly obeyed at hydrogen pressures greater than $10^{-2} \mathrm{~cm} \mathrm{Hg}$ (see Figure 14).

Sievert's law constant varies slightly with temperature ranging from 14.3 to $17.7 \mathrm{ppm} \mathrm{H} \times\left(\mathrm{P}_{2}, \mathrm{~cm} \mathrm{Hg}\right)^{-1 / 2}$ over the temperature range of 297 to $401^{\circ} \mathrm{C}$. The hydrogen solubility is expressed by

$$
\log \mathrm{H}_{2} \text { solubility }(\mathrm{ppm})=-\frac{3180}{\mathrm{~T}(\mathrm{OK})}+6.52
$$

and the equilibrium hydrogen pressure at saturation by

$$
\log \mathrm{P}_{\mathrm{H}_{2}}, \mathrm{~cm}=-\frac{6400}{\mathrm{~T}\left(\mathrm{O}_{\mathrm{K}}\right)}+10.82
$$

over the temperature range of $296 \mathrm{C}$ to $406 \mathrm{C}$ for systems containing less than 25 ppm oxygen (see Figures 15 and 16).

\section{Documentation}

The Solubility of Hydrogen in Liquid Sodium - APDA-241. 


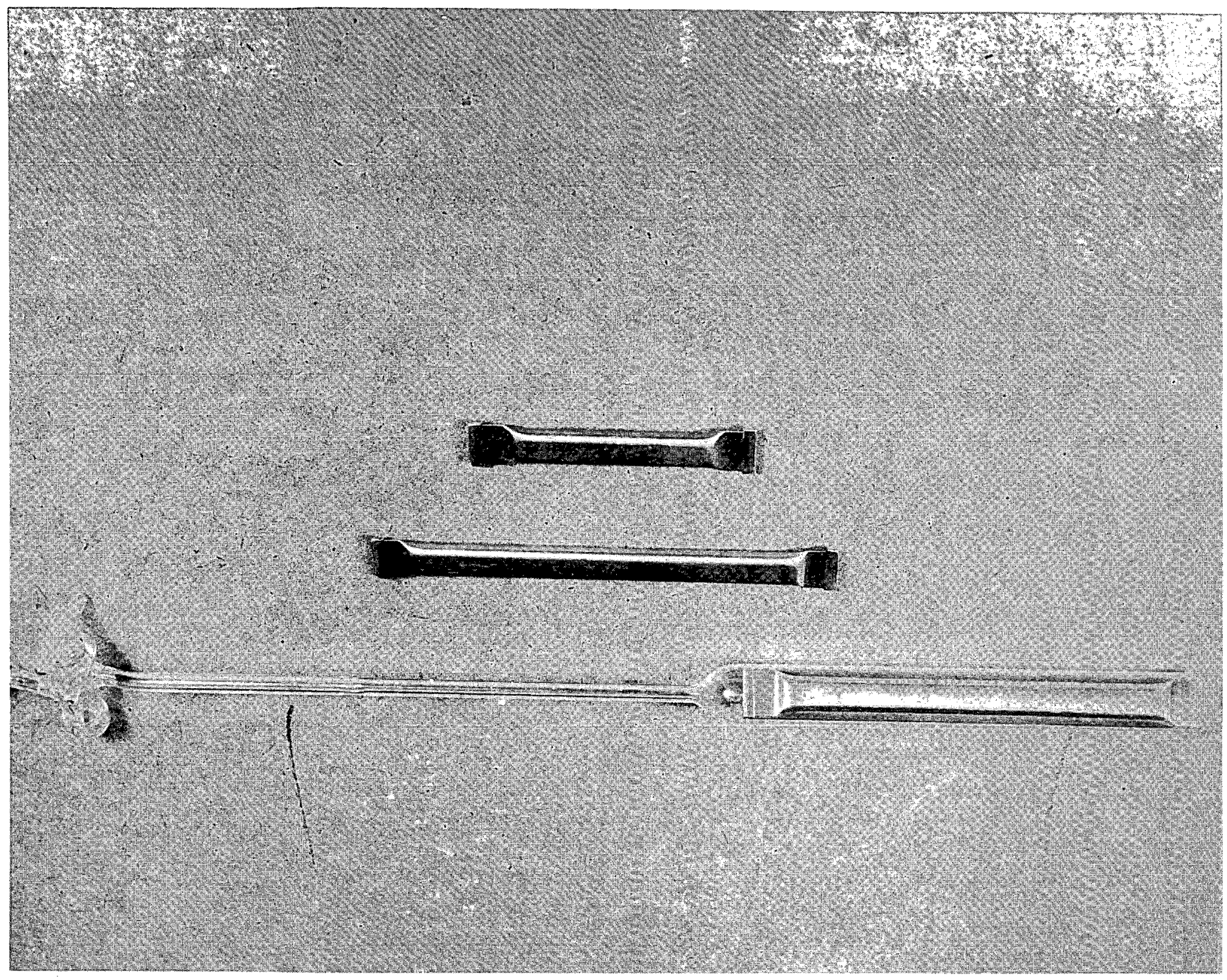




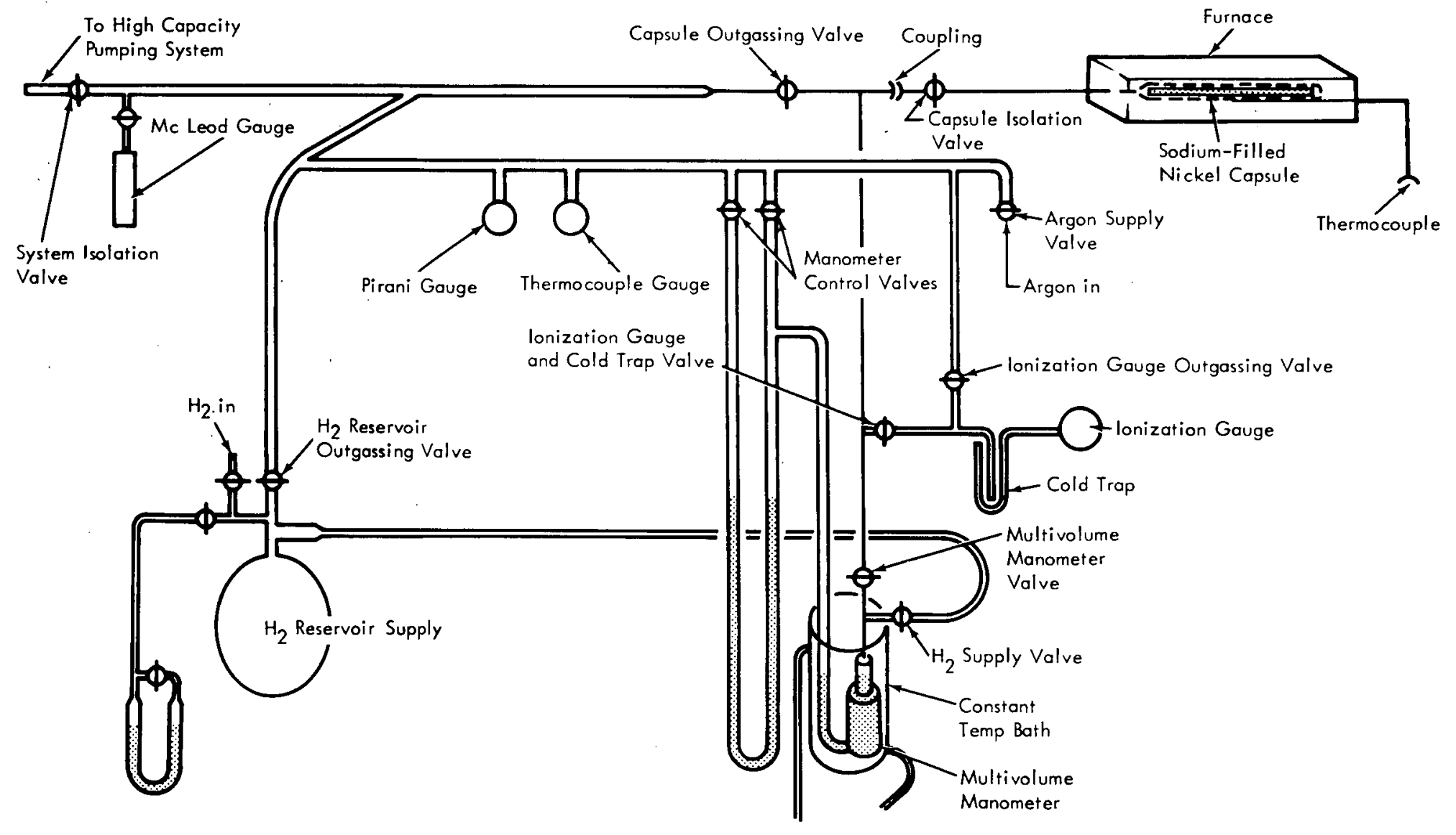




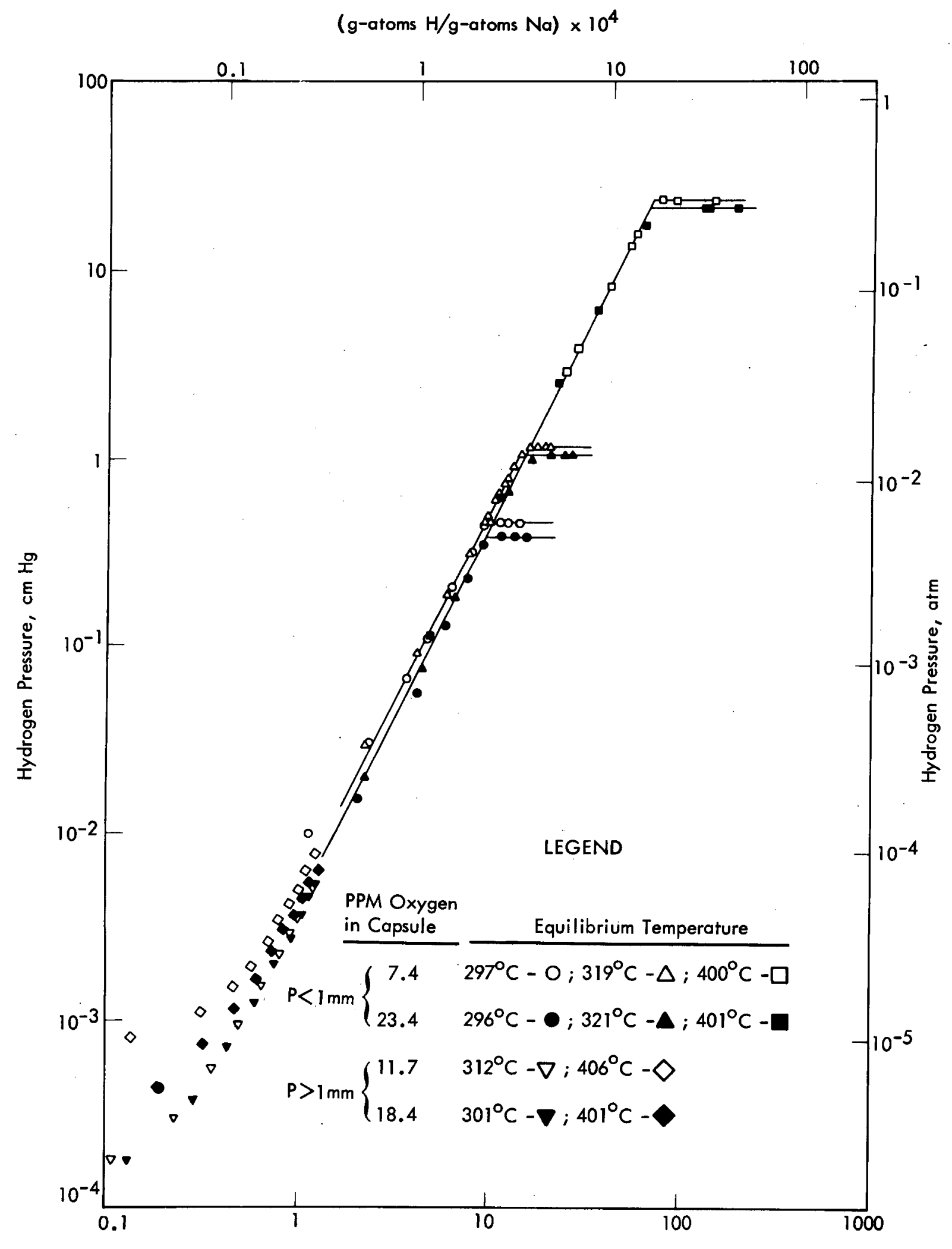

Hydrogen Concentration, ppm

FIG. 14 HYDROGEN SOLUBILITY IN LIQUID SODIUM 


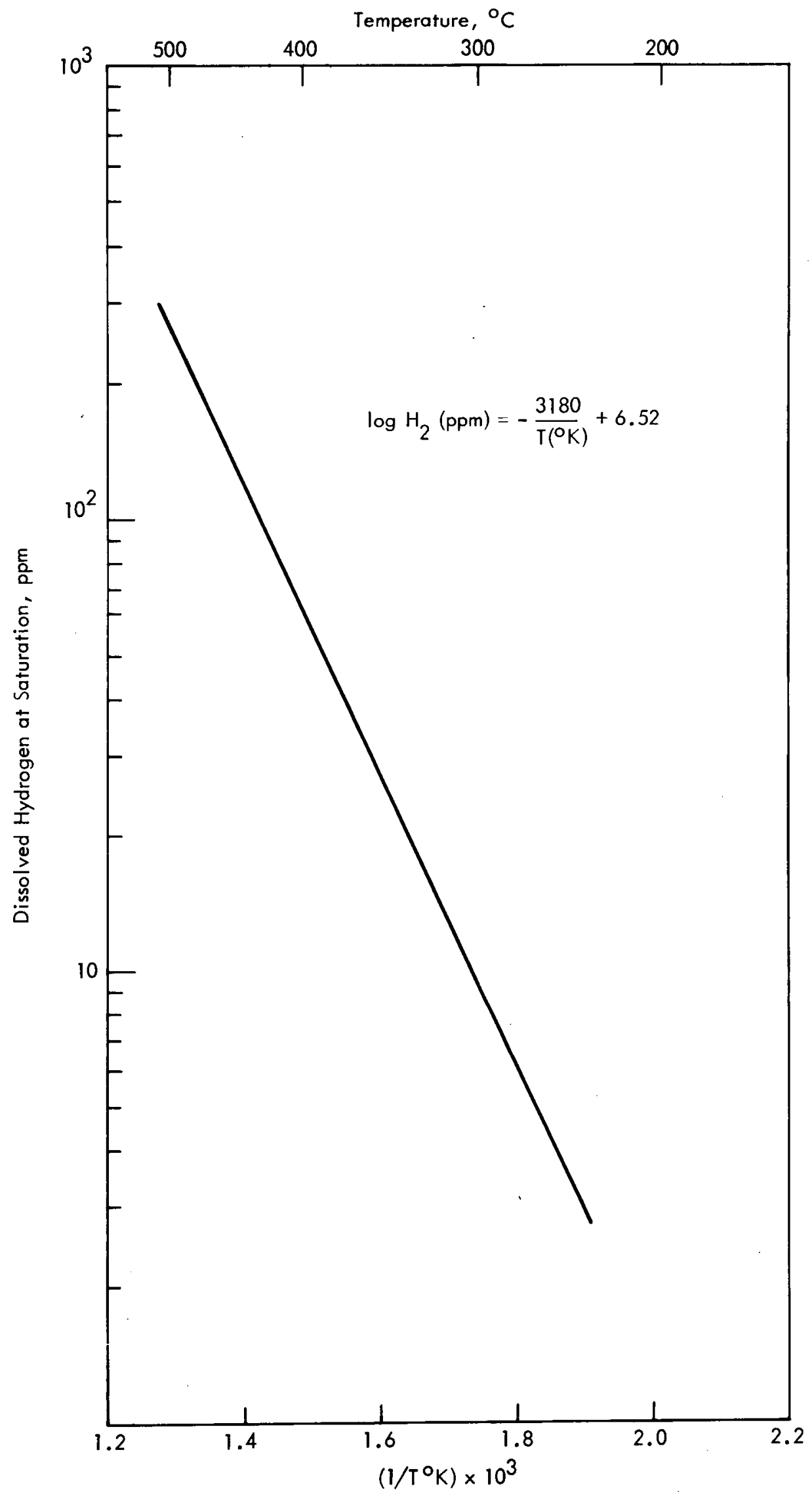

FIG. 15 SOLUBILITY OF HYDROGEN IN SODIUM AS A FUNCTION OF TEMPERATURE 


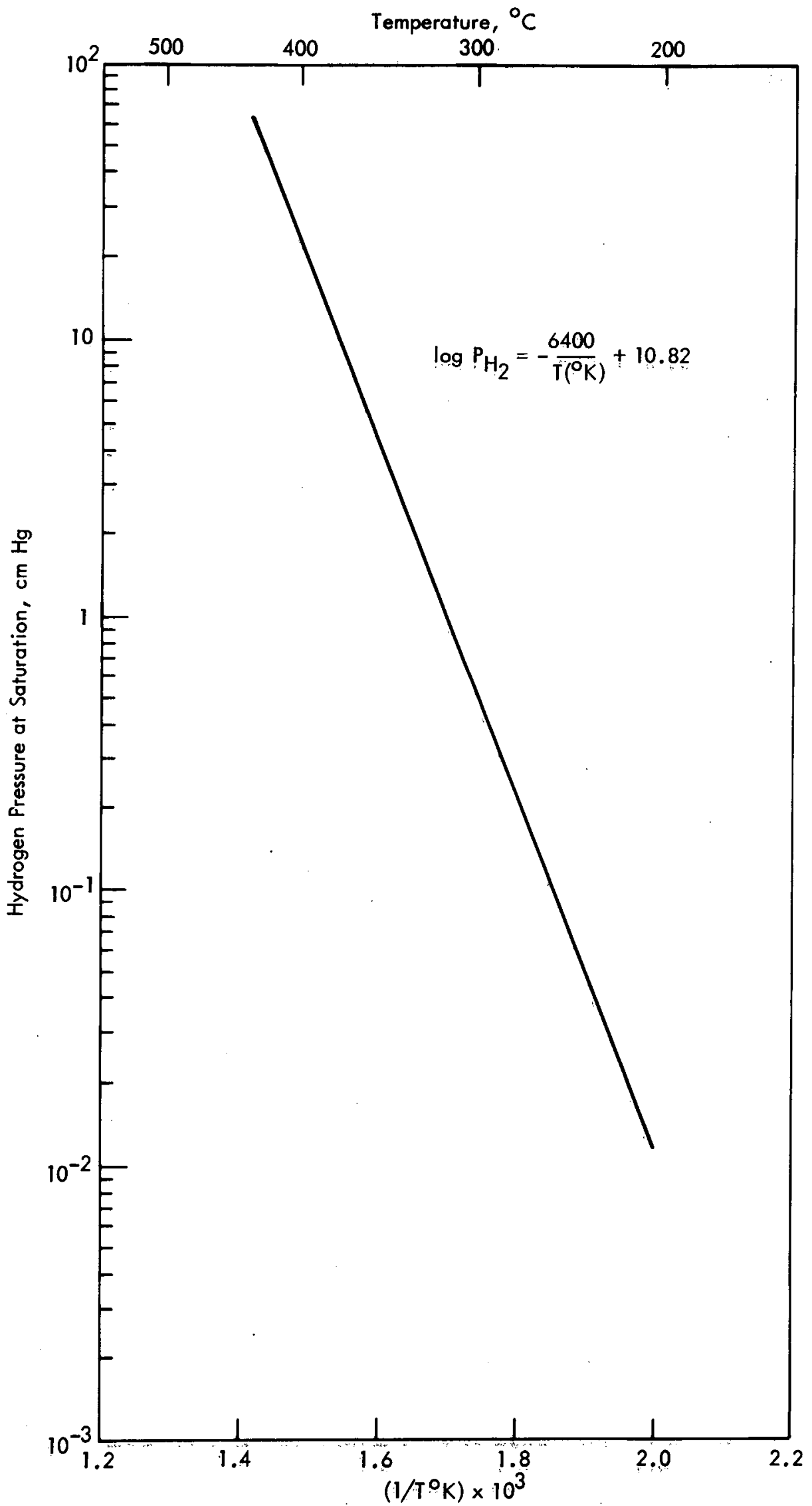

FIG. 16 EQUILIBRIUM HYDROGEN PRESSURE FOR SATURATED SODIUM AS A FUNCTION OF TEMPERATURE 
III. B - THE SOLUBILITY OF SODIUM CARBONATE IN SODIUM

As part of the program to determine the physical and chemical behavior of sodium and its impurities, studies of the solubility of sodium carbonate in liquid sodium were conducted at $150^{\circ} \mathrm{C}, 275^{\circ} \mathrm{C}$, and $400^{\circ} \mathrm{C}$.

\section{Test Program}

About 3 pounds of commercial grade sodium was melted and introduced to the still; the entire apparatus was sealed and evacuated. Distillation time was 2 to 3 hours. Thereafter the distilled sodium was recycled for distillation several times before introduction to the solubility apparatus.

One gram of the $\mathrm{Na}_{2} \mathrm{CO}_{3}$ thus prepared was introduced into the solubility apparatus (corresponding to $1000 \mathrm{ppm}$ of $\mathrm{Na}_{2} \mathrm{CO}_{3}$ ), stirred overnight, and the sodium sampled. Total alkalinity and sodium carbonate determinations were performed on the mercury-insoluble residue from the amalgamation by a differential titration technique using a recording titrimeter.

\section{Conclusions}

Results of the se determinations indicated the solubility of carbonate sodium to be $24.4 \mathrm{ppm}$ at $150^{\circ} \mathrm{C}, 37.9 \mathrm{ppm}$ at $275^{\circ} \mathrm{C}$, and $51.0 \mathrm{ppm}$ at $400^{\circ} \mathrm{C}$ with standard deviations of $4.8,5.2$, and 1.6 , respectively.

\section{Documentation}

This work is documented in the APDA quarterly reports and in APDA-184, "The Solubility of Sodium Carbonate in Sodium," published in August, 1968. 


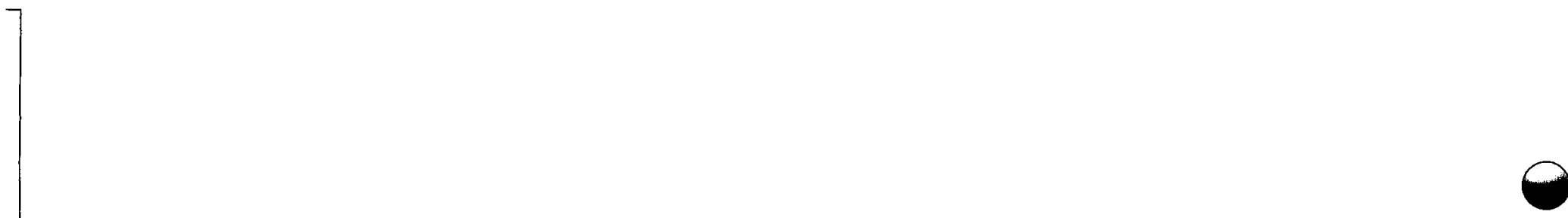

•

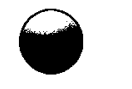

$$
\ldots
$$




\section{C - COVER GAS IMPURITIES--HYDROGEN GETTERING IN GAS SAMPLE LINES}

The objective of this job was to determine the quantity and composition of deposits collected in the cover gas sampling line of APDA's Sodium Technology Loop in order to estimate the error in the cover gas analysis for hydrogen as determined by a gas chromatograph.

\section{Test Program}

A schematic of the sampling system is presented in Figure 17. After 82 days of operation this sampling system was removed and analyzed for sodium and hydrogen.

The total amount of hydrogen in the sampling system was equivalent to not more than $22 \mathrm{ppm}$ hydrogen in the sample stream when averaged over the 82 days the system was in operation. Over the same period, the timeaveraged hydrogen concentration of the gas reaching the chromatograph was approximately $29 \mathrm{ppm}$. The maximum error involved in the sampling system averaged over this period was $43 \%$. The source of error is in the final filter section where the sample gas cools to room temperature; $95 \%$ of the hydrogen is estimated to be in this section.

\section{Conclusions}

Sampling of the cover gas above the sodium is extremely difficult because of the gettering of hydrogen by sodium in the gas sample lines.

\section{Documentation}

This work is reported in the following Quarterly Technical Progress Reports on AEC-Sponsored Activities: APDA-232, APDA-234, APDA-236, and APDA-242. 


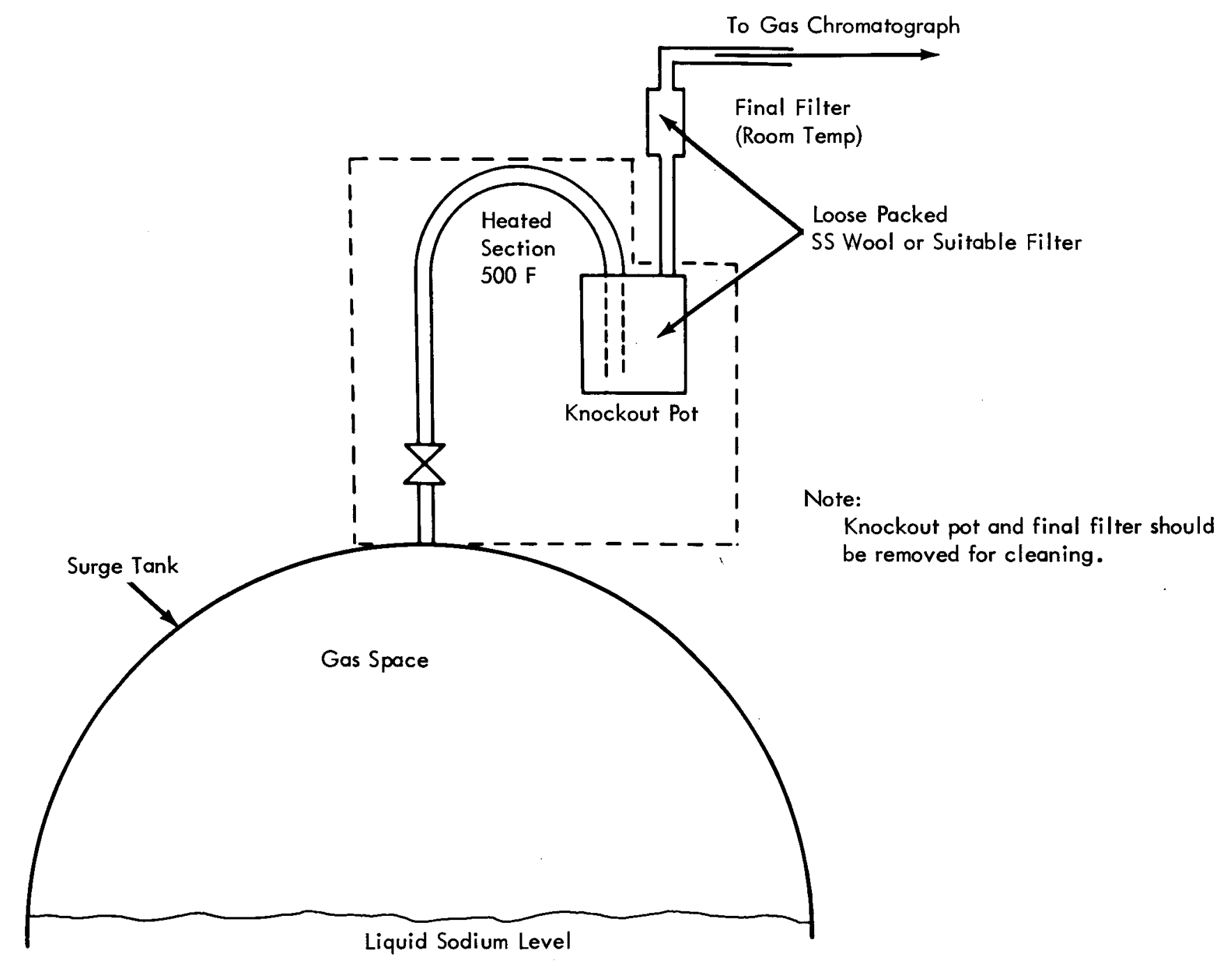

010268

FIG. 17 ARRANGEMENT OF THE GAS SAMPLE LINE FOR THE SODIUM TECHNOLOGY LOOP 
SECTION IV

SAMPLING AND ANALYSIS OF SODIUM 
$\theta$

• - 


\section{A - ANALYTICAL METHODS}

\section{Determination of Oxygen in Sodium}

\section{a. APDA Technique}

The development of a suitable analytical method for the determination of oxygen in sodium involves care in sampling to reduce contamination, the development of methods to quantitatively separate oxygen-containing compounds from an approximate ten thousandfold excess of sodium, and development of a sensitive, reliable method for quantitatively measuring the oxygen.

The APDA method consists of separating the oxygen from insoluble residues by amalgamation and extraction with mercury. The oxygenbearing residue is dissolved in deionized water, titrated with sulfuric acid in the presence of excess sodium hydroxide using a modified methyl red indicator, and the oxygen concentration is calculated from the total alkalinity. The procedure is applicable to the determination of 10 to $100 \mathrm{ppm}$ oxygen in metallic sodium with a relative standard deviation of $10 \%$.

This method is described in the APDA Quarterly Progress Reports and in a topical report (see Documentation).

b. Uranium Gettering Technique

APDA conducted a program to evaluate the proposed Brookhaven National Laboratory technique for measuring oxygen in sodium using uranium as a getter metal in the APDA Sodium Technology Loop.

\section{(1) Test Program}

Twelve uranium specimens which had been exposed to static sodium for 1 hour at $500^{\circ} \mathrm{C}$ were obtained from BNL. The specimens, designated $A_{1}, B_{2}, C_{3}, E_{2}, F_{3}$, and $G_{1}$, were cleaned by electropolishing and weighed prior to experimentation. All the specimens were $0.508 \mathrm{~cm}$ thick by $1 \mathrm{~cm}$ wide by $12.5 \mathrm{~cm}$ long with a net surface area of $26.3098 \mathrm{~cm}^{2}$, with the exception of Specimen $\mathrm{C}_{3}$, which was $0.508 \mathrm{~cm}$ thick by $1 \mathrm{~cm}$ wide by $12.35 \mathrm{~cm}$ long and had a net surface area of $25.9946 \mathrm{~cm}^{2}$.

Two experiments were conducted at two oxygen levels by exposing the specimens, three at a time, to the sodium of the APDA Sodium Technology Loop using a specimen holder of 3/4-inch stainless steel tubing. The experimental conditions and test results are shown in Table 1. 
Sodium Conditions

Flow through Sample Holder, gpm

Temperature, ${ }^{\circ} \mathrm{C}(\mathrm{F})$

Oxygen Level, * ppm

$$
\begin{gathered}
1 / 2 \\
485(905) \\
6.7
\end{gathered}
$$

2

Exposure Time of Specimens, hr

Pretest Weight of Specimens, g

Weight Gain of Specimens, g

Average Weight Gain, $\mu \mathrm{g} / \mathrm{hr} \mathrm{cm}^{2}$

Predicted Oxygen Concentration ${ }^{* *}$

by Uranium Gettering
$\mathrm{A}_{1} 11.3897$

$\mathrm{B}_{2} 11.3588$

C3 11.4429

$\begin{array}{ll}\mathrm{A}_{1} & 0.0050 \\ \mathrm{~B}_{2} & 0.0058 \\ \mathrm{C}_{3} & 0.0045\end{array}$

97.3

6.0
$1 / 2$

485 (905)

9.5

2

$\mathrm{E}_{2} \quad 11.7364$

$F_{3} 11.0974$

$\mathrm{G}_{1} 11.1063$

$\mathrm{E}_{2} \quad 0.0112$

$\mathrm{F}_{3} \quad 0.0119$

$\mathrm{G}_{1} 0.0128$

194.93

12.0

* Calculated value as $\mathrm{Na}_{2} \mathrm{O}$, as determined by the mercury amalgamation method

*** Based on a rate constant of $16.3 \mu \mathrm{g} / \mathrm{hr} \mathrm{cm}^{2}$ at $500^{\circ} \mathrm{C}$ as established by BNL (Reference BNL-50111, pp 41-46, 1968)

\section{(2) Conclusions}

This evaluation demonstrated the feasibility of the uranium gettering technique for monitoring the oxygen concentration in a dynamic sodium system. The work is documented in Quarterly Report of AECSponsored Activities, April-June, 1969 - APDA-242.

\section{Determination of Hydrogen in Sodium}

It is hypothesized that hydrogen can be present in reactor sodium. in the form of sodium hydride, sodium hydroxide, dissolved hydrogen, and possibly hydrocarbons. It is imperative, therefore, that sensitive analytical methods be developed to distinguish among the hydrogen species present. 
The method used at APDA is a 2 -stage vacuum reflux technique utilizing mercury as the refluxing medium (see Figure 18). The evolved hydrogen is measured quantitatively by gas chromatography. The mercury acts as a sequestering agent, removing the highly reactive sodium from the system by amalgamation, thus preventing re-formation of sodium hydride by the liberated hydrogen. By carefully controlling the amalgamation temperature, hydroxide hydrogen, nonhydroxide hydrogen, and total hydrogen can be determined. These results can, in turn, be used to more accurately evaluate the sodium monoxide contents of a sodium sample. The procedure is applicable to the 0.2 to $100 \mu \mathrm{g}$ of hydrogen in sodium with a relative standard deviation of $\pm 5 \%$. (See Documentation).

\section{Determination of Carbon in Sodium}

The need to monitor the carbon content of large sodium systems used in the LMFBRs and even in small test loops such as the APDA Sodium Technology Loop has necessitated the development of a reliable method for determining total carbon in sodium. The concentration range is 10 to $100 \mathrm{ppm}$.

The APDA analytical method for the determination of total carbon in sodium metal is based on a stepwise conversion of the total carbon in the sodium sample to sodium carbonate to carbon dioxide, which is collected at liquid nitrogen temperature and subsequently measured by gas chromatography (see Figure 19). A sample of the sodium is placed in a quartz combustion system and heated to $1100^{\circ} \mathrm{C}$ within 1 hour, with an additional residence time of 1 hour to ensure complete reaction. An atmosphere of approximately $10.75 \mathrm{ml} / \mathrm{min}$ of oxygen in helium is used during the heating process. The sample is protected from atmospheric contamination by loading the combustion tube in an oxygen-free glove box.

A representative series of replicate sodium samples analyzed by this method had a standard deviation of $\pm 3 \mathrm{ppm}$ and is applicable to the determination of carbon in sodium in the concentration range of 10 to 150 ppm in 0.2 to $0.4 \mathrm{~g}$ samples of sodium. The method is thought to be capable of giving reasonably precise results with a relative error estimated at being in the range of \pm 5 to $10 \%$. This method is described in a topical report (see Documentation).

\section{Determination of Carbonate Carbon in Sodium}

The term carbonate carbon refers to the carbon which is present in the form of sodium carbonate, or exists as a chemical species capable of evolving carbon dioxide under the dissolution-evolution conditions of the recommended procedure. Because relatively small quantities of carbonate are present in the sodium from nuclear reactors, the standard methods of detecting this impurity are not suitable. 


\section{a. Test Program}

The APDA method is based on the carefully controlled dissolution of a sodium sample in water, the evolution and collection of carbon dioxide, and the measurement of the carbon dioxide by gas chromatography. An investigation of the relative merits of water dissolution and alcohol dissolution resulted in the selection of water as the solvent.

\section{b. Conclusions}

The analytical results from replicate determinations of carbonate carbon on three samples of sodium metal showed a standard deviation between $0.2 \mathrm{ppm}$ and $0.26 \mathrm{ppm}$; a relative standard deviation of $4 \%$ to $7 \%$ would indicate that a reasonably good precision can be obtained at low levels of carbonate carbon in sodium.

This work was documented in a topical report (see Documentation).

\section{Documentation}

1. The Determination of Oxygen in Sodium Metal - APDA-163, July 2, 1965.

2. The Determination of Hydrogen in Sodium Metal - APDA-183, June 1966.

3. Determination of Carbon in Sodium by a High-Temperature Combustion Method Utilizing Gas Chromatography - APDA-164, November 1964.

4. Determination of Carbonate Carbon in Sodium Metal - APDA-166, January 1965. 


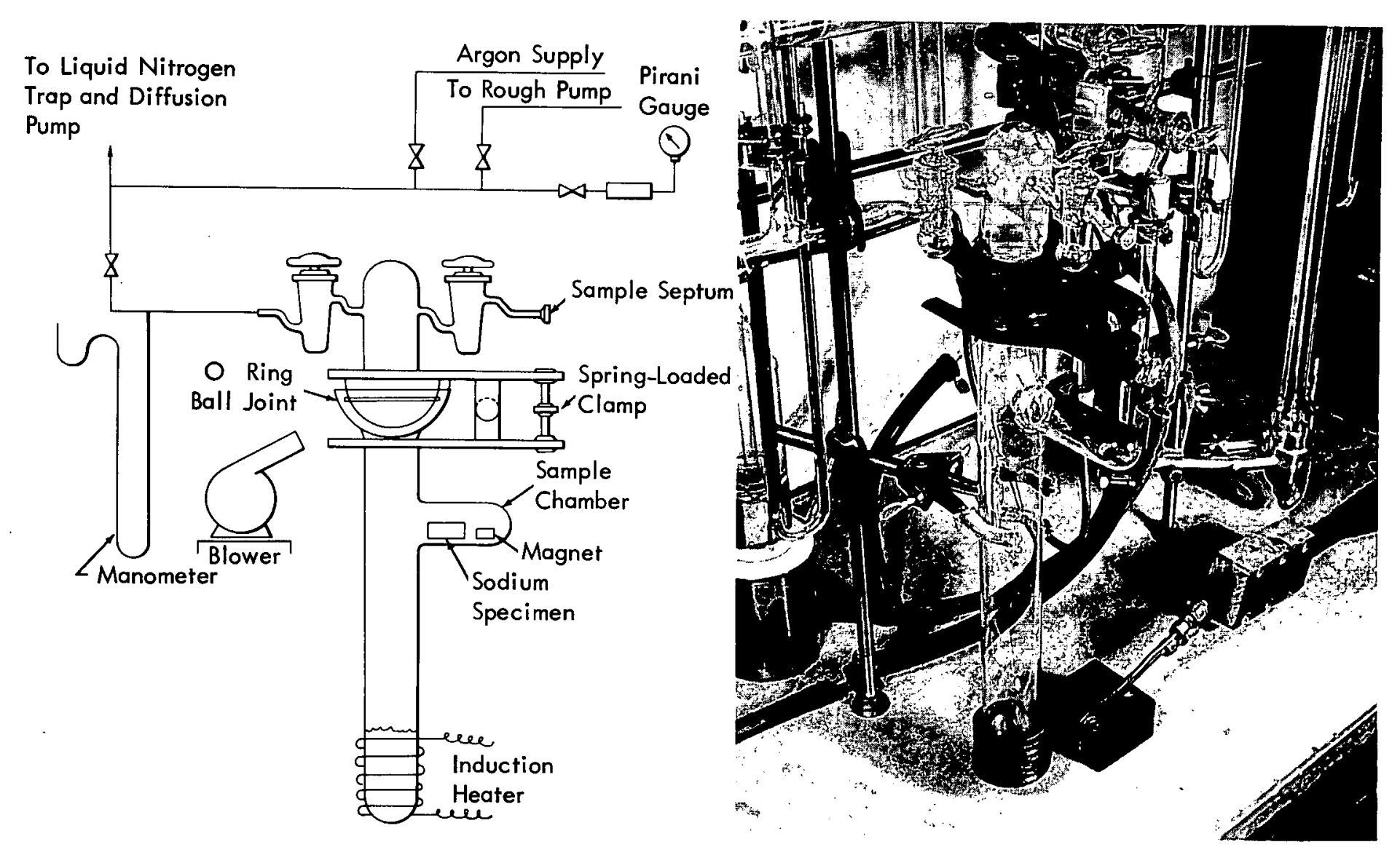




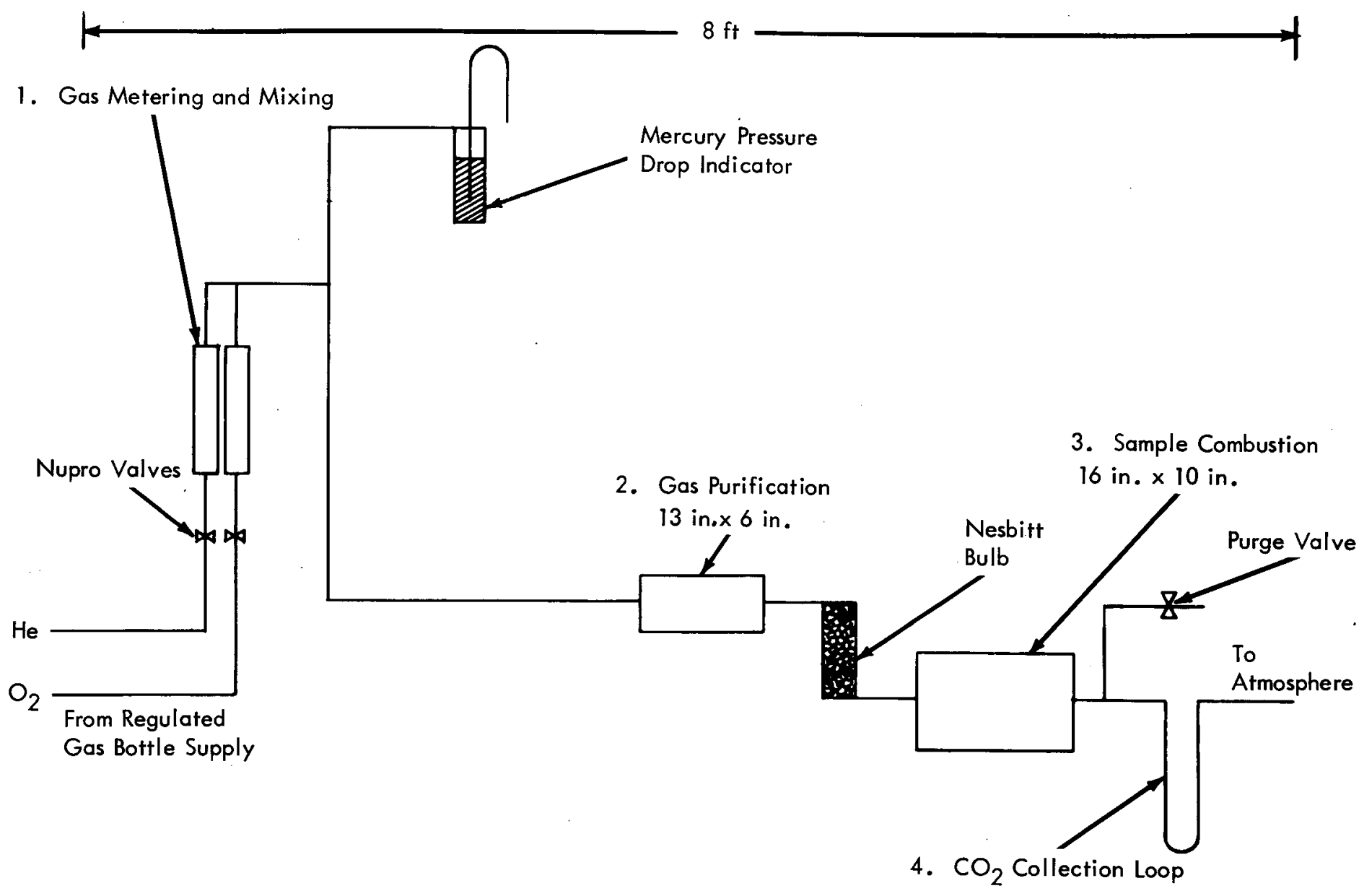




\section{IV.B - SAMPLING RELIABILITY STUDIES}

Extensive studies were conducted at APDA to determine the sampling and analysis reliability for measuring the oxygen content of loop sodium using the bypass freeze tube sampling technique and the mercury amalgamation procedure for oxygen. This effort was culminated by the publication of two topical reports (see Documentation).

A similar but much less extensive study of the reliability of sampling procedures for hydrogen was also conducted and the results published in APDA Quarterly Progress Report on AEC-Sponsored Activities, APDA-242.

\section{Oxygen Sampling and Analysis}

a. Test Program

Sodium samples were taken from two sampling stations enclosed in a glove box continuously purged with a stream of purified argon. Both pinched and nonpinched bypass freeze tubes were used.

\section{b. Conclusions}

The effect of oxygen segregation along the length of a nonpinched sample tube is more pronounced at Station 1 than at Station 2. At Station 1, impurity segregation was detectable at each of the three nominal oxygen concentration levels $(11,47$, and $76 \mathrm{ppm})$. At Station 2, impurity segregation was detectable only at the high oxygen concentration. It is believed that the segregation of oxygen in the sample tube is caused by a nonuniform cooling rate along the length of the sample tube. There was no detectable site-tosite variation at Station 2 for the $11-$ ppm and $47-\mathrm{ppm}$ levels of oxygen above the amount which could be attributed to chance alone. This means there was no detectable correlation between the measured oxygen and site location over the length of the sample tube, but does not imply that no segregation occurred - only that the data are not sufficient to detect segregation against the background of random variation.

For the low level of oxygen in sodium (nominal $11 \mathrm{ppm}$ ), Station 1 is recommended for obtaining reliable sodium samples in nonpinched sample tubes. An arithmetic average of the site analyses was used as an estimate for oxygen concentration of the sampled sodium. At this concentration, an estimated precision for the combined sampling and analysis is about $\pm 8.8 \%$ at the $95 \%$ confidence level. 
For the medium level of oxygen (nominal $47 \mathrm{ppm}$ ) in sodium, eithe $r$ of the two sampling stations could be used for obtaining reliable sodium samples in nonpinched sample tubes, although Station 1 is preferable. An arithmetic average of the site analyses was used as an estimate for oxygen concentration of the sampled sodium. An estimated precision for the combined sampling and analyses at this concentration is $5.6 \%$ and $10 \%$ for Station 1 and 2 , respectively, at the $95 \%$ confidence level.

For the high level of oxygen (nominal $76 \mathrm{ppm}$ ) in sodium, the sampling and analysis technique using a nonpinched sample tube was not adequate for reliable sodium samples at either of the two sampling stations. A significant impurity segregation occurred over the length of the sample tube at both sampling stations (see Figures 20 and 21). A significant difference in the tube averages (arithmetic average computed from individual site analyses) from each station was detectable, and the grand means of the sampling tube averages from the two stations were also significantly different $(\overline{\bar{X}}=79.2 \mathrm{ppm}$ at Station 1 and $\overline{\bar{X}}=72.62 \mathrm{ppm}$ at Station 2).

The technique of hot-pinching the sample tube into segments where the entire sodium is consumed in the chemical analyses was found to be very effective in reducing the scatter in the individual chemical analyses (see Figure 22). Although a segregation effect, or site-to-site variation, was still detectable at both sampling stations for the modified hotpinched sample tubes at the nominal 30-ppm oxygen level, the extent of variability in the individual analyses was smaller than the estimated precision for the chemical analytical method alone (10\% relative standard deviation), showing that the hot-pinching technique of sampling significantly reduced the error due to the sampling procedure. Therefore, for the 7-to$30 \mathrm{ppm}$ oxygen range, the technique of hot-pinching is adequate for obtaining reliable results from either of the two stations. The combined sampling and analysis error lies within the range of the estimated error of the analytical technique alone (10\% relative standard deviation) even if an individual site analysis of the hot-pinched sample tube is used as an estimate for the oxygen concentration of the sampled sodium.

Thus, if the sample tube averages computed from at least five individual site analyses are used to estimate the oxygen concentration of the sampled sodium, then for the levels of oxygen evaluated there is no distinct advantage in hot-pinching the sample tube. However, hot-pinching could be used to reduce the number of site analyses used in estimating the concentration of the sampled sodium. Additional studies should be made at higher levels (50-100 ppm) of oxygen with hot-pinched tubes to establish the precision for the combined sampling and anlysis procedure. 


\section{Round Robin for Oxygen in Sodium}

A round robin program involving five laboratories selected by the sponsor for their experience with the mercury amalgamation procedure was conducted for measuring oxygen in sodium. The objective of the program was to establish the precision of a revised mercury amalgamation analytical procedure as prepared by a cognizant ASTM subcommittee.

A statistical evaluation of the round robin results using the proposed procedure indicate a relative standard deviation of $\pm 30 \%$ at the 7 ppm oxygen level and $\pm 15 \%$ at the $30 \mathrm{ppm}$ oxygen level. Results of the round robin program also demonstrated that the pinched tube method of preparing sodium samples (see Figure 23), developed by APDA, resulted in samples which were homogeneous within $\pm 25 \%$ at a $95 \%$ confidence level.

Graphical analyses of the data indicate that the procedure and its execution in some of the participating laboratories can and should be improved.

The reproducibility of the analytical blank was investigated and results indicate a need for further investigation into the source of its variability. Additional work needed to improve the mercury amalgamation includes analytical blank and mercury purity studies.

A revised amalgamation procedure, based on the experience gained from this round robin, was presented for consideration.

This work was also documented in a topical report (see Documentation)

\section{Hydrogen Sampling Reliability}

The objective of this test program was to establish the precision of the combined sampling and analysis procedure (bypass freeze tube sampling and mercury amalgamation procedure for hydrogen, APDA-183). Table 2 presents data indicating the reproducibility of the above-mentioned sampling and analysis procedure for the two sampling stations located in the APDA Sodium Technology Loop. Figure 24 illustrates the site-to-site variation of hydrogen along a sample tube taken from Station 2.

As stated in Section II. B, a discrepancy was observed between the hydrogen concentration of cold-trapped loop sodium determined by the APDA hydrogen detector and that determined by the above described sampling and analysis procedure. This has led to the concensus at APDA that there is a significant blank contribution from the sampling tubes in the mercury amalgamation procedure. Some very preliminary experiments in sample tubes free of sodium supports this conclusion, although the precision of 


\section{TABLE 2 - DATA FROM HYDROGEN SAMPLING RELIABILITY STUDIES}

Sample Tube

Average, ppm

Hydrogen
Standard Deviation of Sample Tube Averages, ppm

First Test Period

Station 1 (18 Tubes)

Hydride Hydrogen

0.95

0.46

Hydroxide Hydrogen

1.97

0.53

Total

2.93

0.66

Station 2 (4 Tubes)

Hydride Hydrogen

0.93

0.32

Hydroxide Hydrogen

1.63

0.22

Total

2. 56

0.52

Second Test Period

Station 2 (11 Tubes)

Hydride Hydrogen

0.53

0.13

Hydroxide Hydrogen

1. 38

0.25

Total

1.90

0.33

NOTE: Three sample sites per sampling tube were used to establish the sample tube average.

the combined bypass tube sampling method and mercury amalgamation method has been measured, no meaningful statement regarding the accuracy can be made at this time.

4. Documentation

1. Sampling and Analysis for Oxygen in Sodium - APDA-246, April 1970.

2. Evaluation of an In-Line Detector for Hydrogen in Sodium APDA - 252.

3. Evaluation of the Proposed ASTM Method for Measuring Oxygen in Sodium Utilizing a Round Robin Program - APDA-238, January 1970. 


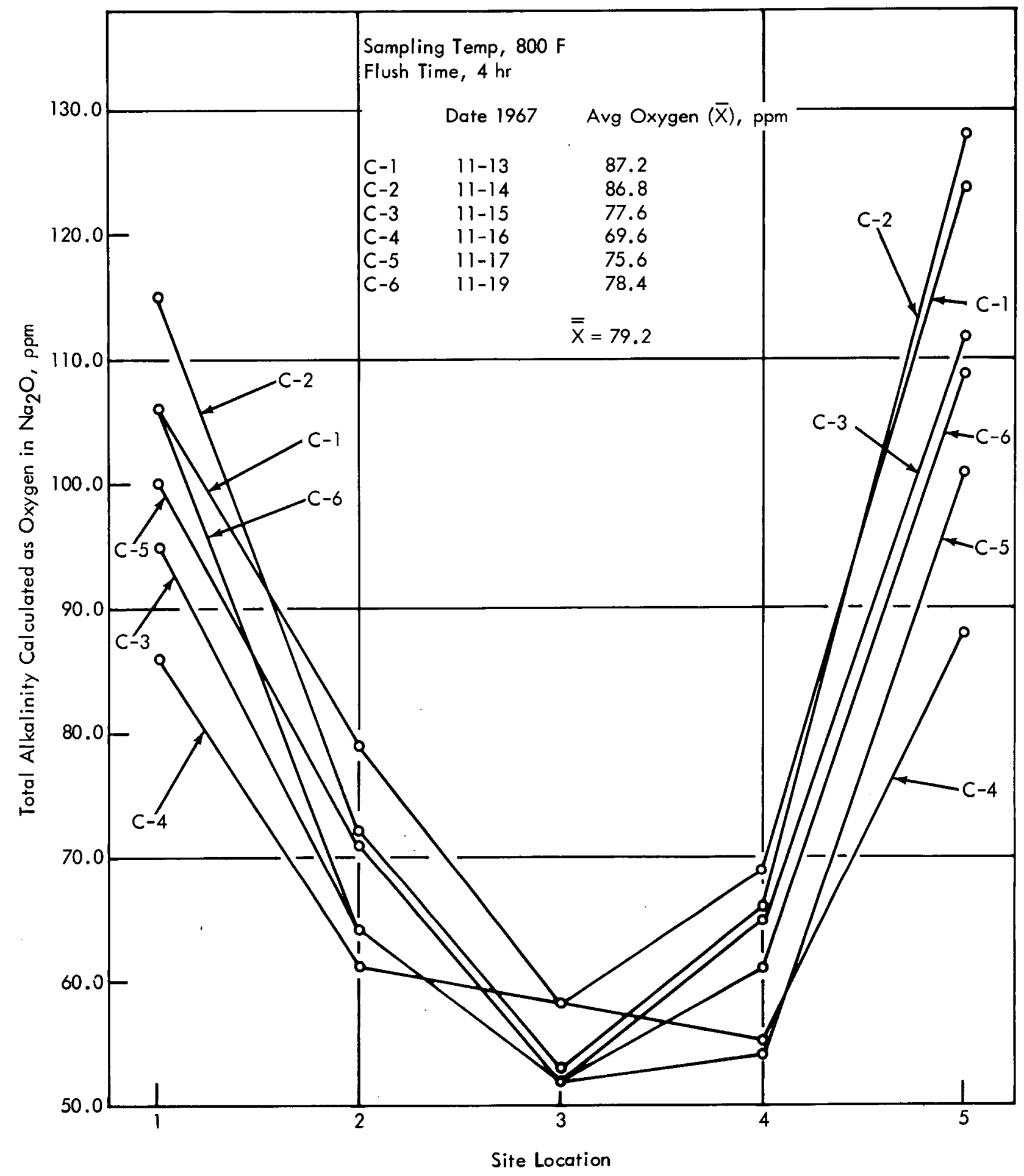

119069

FIG. 20 OXYGEN CONCENTRATION VERSUS SITE LOCATION FOR SAMPLES FROM STATION 1-NONPINCHED SAMPLE TUBE, HIGH-LEVEL OXYGEN 


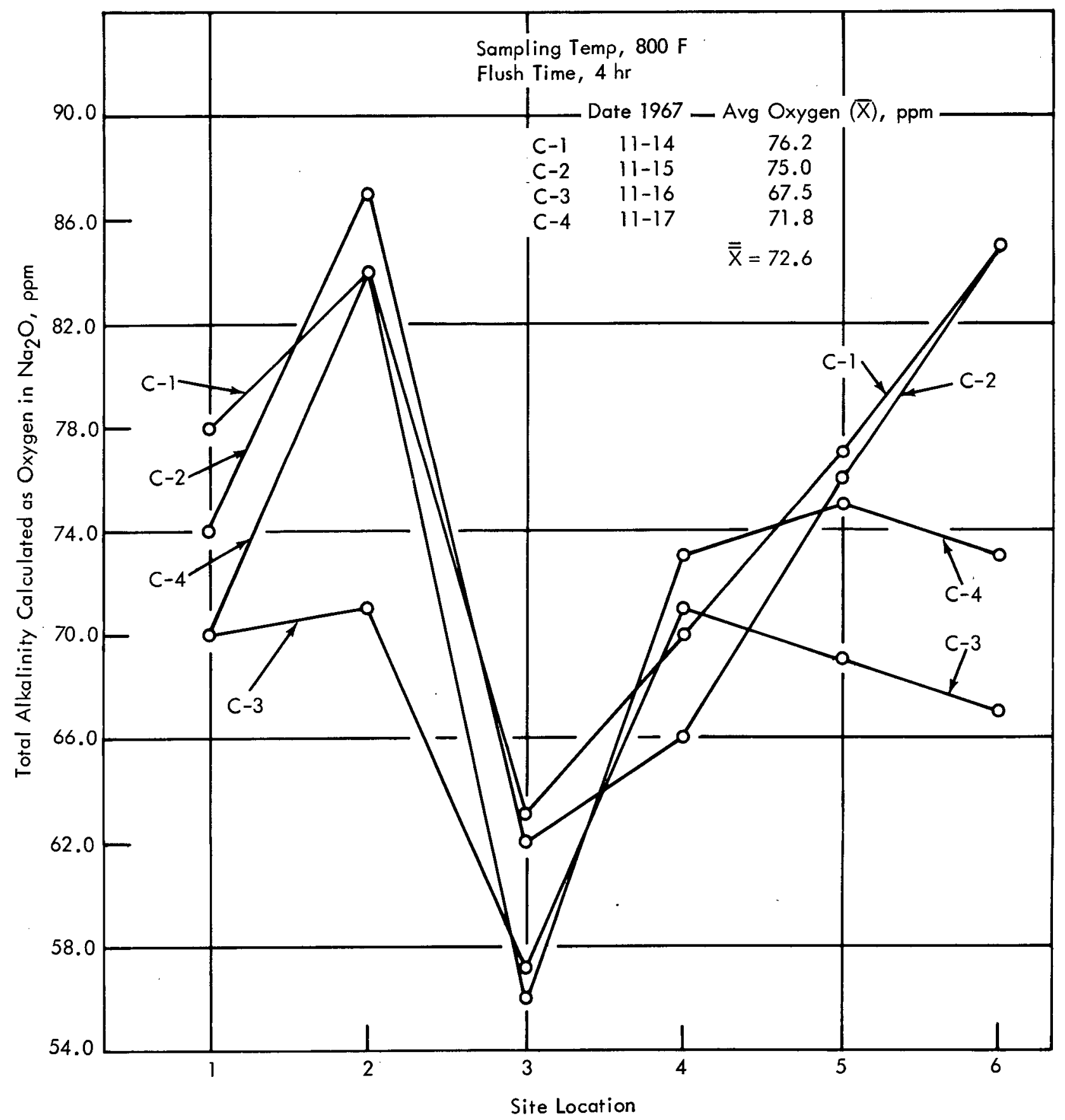

117969

FIG. 21 OXYGEN CONCENTRATION VERSUS SITE LOCATION FOR SAMPLES FROM STATION 2-NONPINCHED SAMPLE TUBE, HIGH-LEVEL OXYGEN 
Nonpinched tube

Hot-pinched tube - - - -

$\square$ Sample tube averages

O Site averages

$\triangle$ Individual analyses

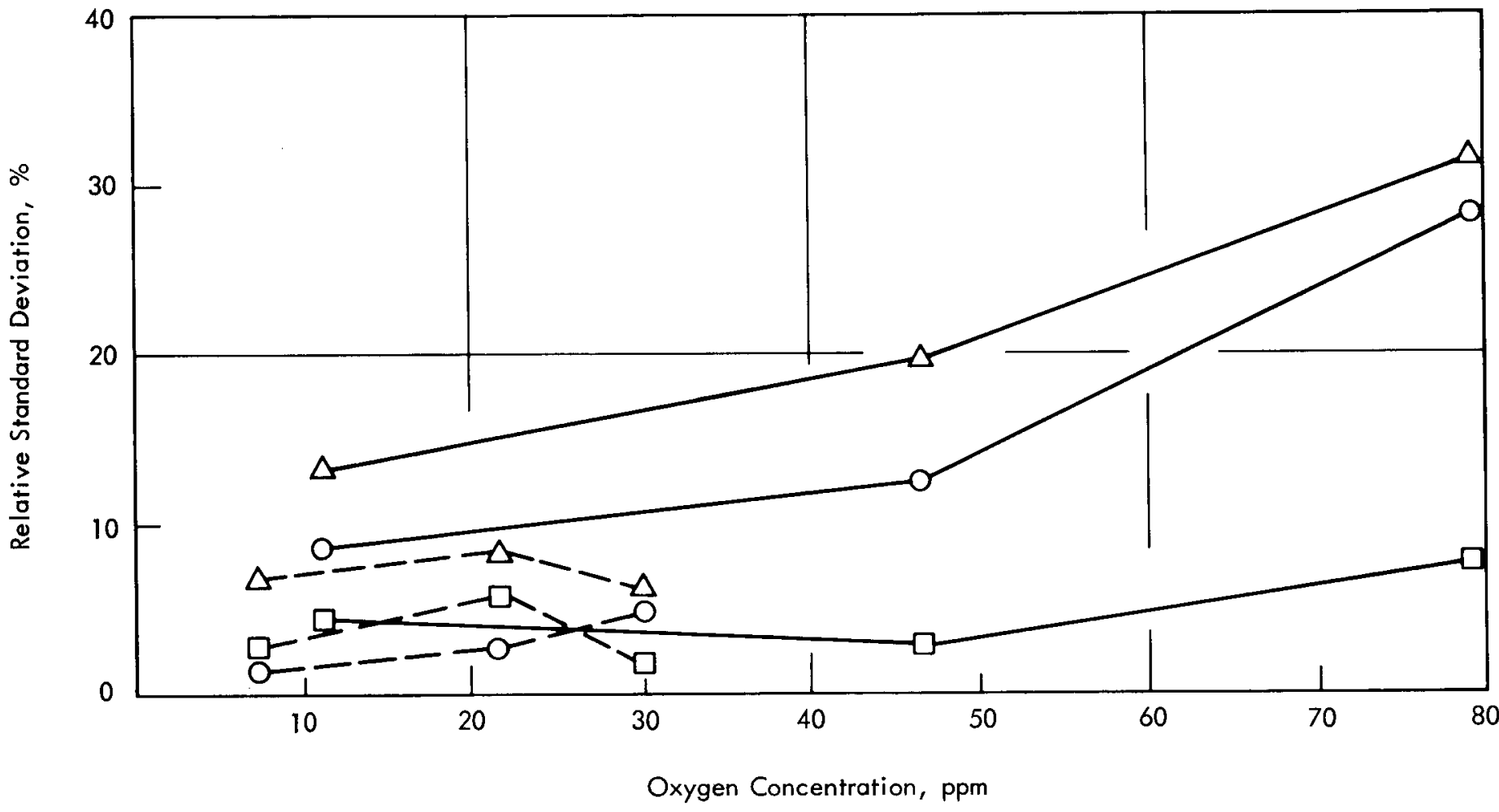

FIG. 22 RELATIVE STANDARD DEVIATION VERSUS OXYGEN CONCENTRATION FOR PINCHED AND NONPINCHED SAMPLE TUBES FROM STATION 1 


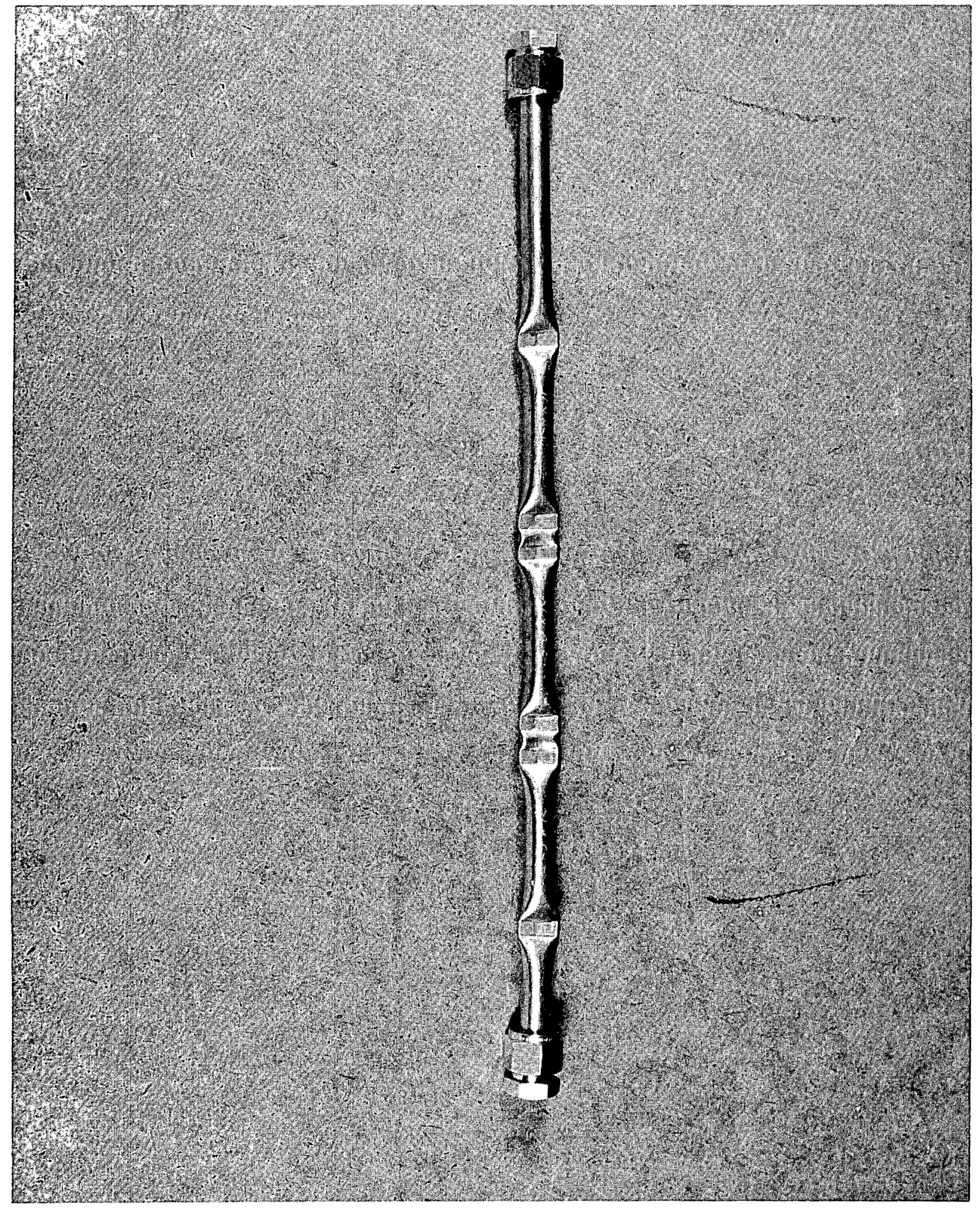

118269

FIG. 23 CAPSULES PREPARED BY THE APDA LABORATORY FOR ASTM ROUND ROBIN ANALYSIS 


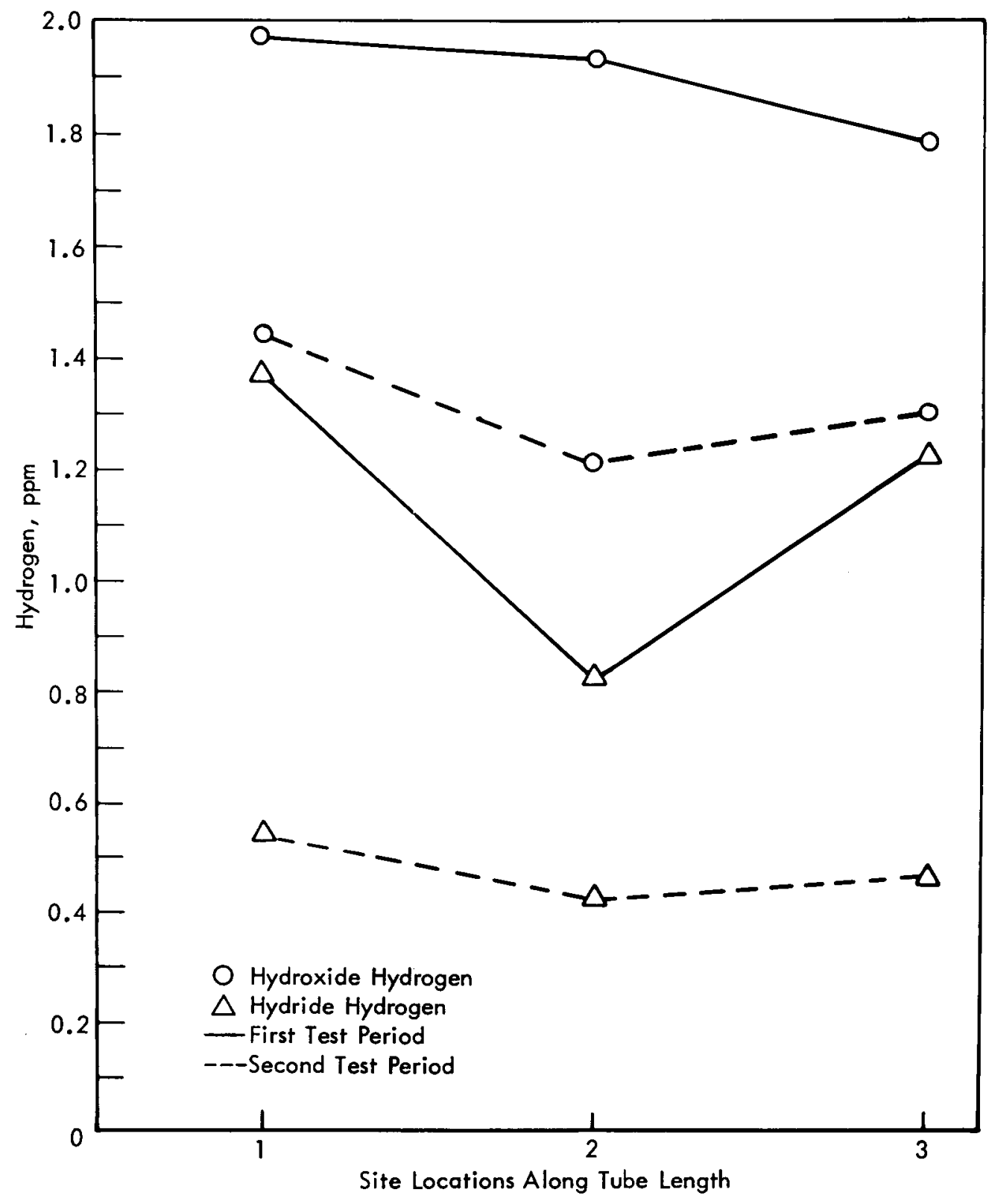

FIG. 24 SAMPLE TUBE SITE AVERAGES - STATION 2 


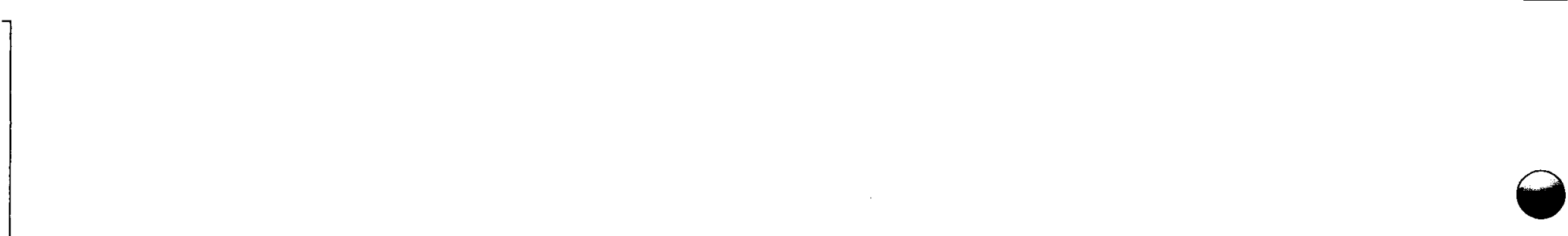

$\theta$

?

•

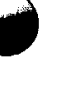


The work summarized in this report represents the combined effort of many individuals over the past several years. The author wishes to specifically acknowledge contributions of the following APDA personnel, past and present:
A. Amorosi
E. Halas
J. W. Balnave
W. A. Heenan
S. Barkhoudarian
E. F. Hill
H. T. Carmichael
C. C. $\mathrm{Hill}^{* *}$
H. V. Chamberlain
R. A. Hunter
W. L. Chase
W. D. Huston
W. H. Jens
J. H. Coleman
R. H. Jones
T. H. Collins
J. O. Kermoshchuk
H. Kitamura***
M. K. Deora
J. E. Knight
J. G. Duffy
L. R. Kovac
J. N. Ferguson
E. C. Kovacic
J. A. Ford
P. S. Lindsey
A. J. Friedland
J. Matte III
A. A. Gordus*
S. A. Meacham
D. M. Green

J. J. Morabito

N. N. Mueller

W. E. McHugh

K. Odajima ${ }^{*}$

J. T. Petrek

G. H. Reicks

H. Rokeberg

M. G. Schaar

C. C. Scott

A. A. Shoudy

S. Siegel

M. Takahashi * $^{*} *$

W. L. Toth

P. Vilinskas

E. R. Volk

J. Wooton

M. A. Ziniuk

The many tests involved in this project were made possible by the Test Operations Section under the able guidance of Mr. J. A. Cameron and a staff of engineers and technicians.

The assistance of the following APDA editorial staff has been invaluable in the documentation of this work:

F. R. Lesch

E. M. Madsen

E. Gordon

C. E. Gump

W. A. MacLaurin

\footnotetext{
* Consultant, University of Michigan

** Consultant, Power Technology

*** Assigned to APDA by Central Research Institute of Electric Power Industry, of Japan
} 
$\bullet$

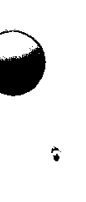

.

$\bullet$

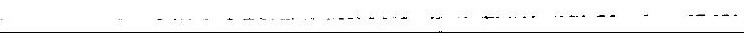

$\cdots$


USAEC-Chicago Operations Office

Director, Contracts Division (2)

G. H. Lee

USAEC - Washington, RDT

Director

Asst. Director, Program Management

Asst. Director, Reactor Engineering

Asst. Director Reactor Technology.

Asst. Director, Plant Engineering

Asst. Director, Nuclear Safety

Project Manager, LMEC

Project Manager, FFTF

Program Manager, LMFBR

Liquid Metal Projects Branch

Chem \& Chem Separations Branch

Reactor Physics Branch

Fuels and Materials Branch

Applications and Facilities Branch

Components Branch

Instrumentation and Control Branch

Systems Engineering Branch

Core Design Branch

Fuel Handling Branch

Special Technology Branch

Reactor Vessels Branch

USAEC-RDT Site Representatives

Senior Site Representative, ANL

Senior Site Representative, AI

Acting Senior Site Representative, IdOO

USAEC-DTIE

R. L. Shannon (3)

USAEC - New York Operations Office

J. Dissler

USAEC - San Francisco Operations Office J. Holliday

Director, LMFBR Programs Office, ANL Director

Director, LMEC, AI

R. W. Dickins on

Aerojet - General Corporation

H. Derow

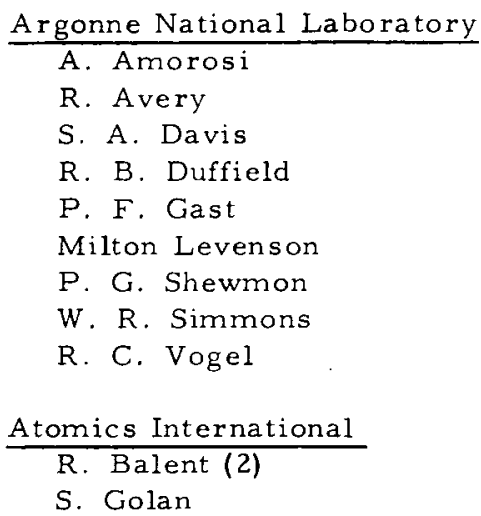

Babcock \& Wilcox Company

(Box 1260, Lynchburg, Va 24505) M. W. Croft

Babcock \& Wilcox Company (Barberton, Ohio)

P. B. Probert

Baldwin-Lima-Hamilton Corp.

(Industrial Equipment Div., Eddystone, $\mathrm{Pa}$ )

J. G. Gaydos

R. A. Tidball

Brookhaven National Laboratory
O. E. Dwyer
D. Gurinsky (2)
K. Hoffman
C. Klamut
L. Newman
A. Romano

Combustion Engineering, Inc.

(Box 500, Windsor, Conn)

W. P. Staker

W. H. Zinn

General Electric Company

(175 Curtner, San Jose, Calif 93125)

K. P. Cohen (3)

General Electric Company (310 DeGuigne, Sunnyvale, Calif 94086)

A. Gibson 
Gulf General Atomic, Div. of Gulf Oil Co. (San Diego, California)

P. Fortescue

M. W. Kellogg Company

(711 Third, New York, New York)

E. W. Jesser

Lewis Flight Prop. Laboratory, NASA

(2l000 Brookpark, Cleveland, Ohio)

C. A. Barrett

Los Alamos Scientific Laboratory

D. B. Hall (2)

G. Waterbury

W. R. Wykoff

MSA Research Corporation

(Callery, Pa 14024)

C. H. Staub

Nuclear Materials \& Equipment Corp.

(Apollo, Pennsylvania)

Z. M. Shapiro

Oak Ridge National Laboratory

(Box X, Oak Ridge, Tennessee)

F. L. Culler (2)

J. H. Devan

D. Gardiner

J. White

Oak Ridge National Laboratory

(Box Y, Oak Ridge, Tennessee)

R. E, MacPhersun, Jr.

Pacific Northwest Laboratory, BMI

E. Astley (5)

Power Reactor Development Company

(1911 First, Detroit, Michigan 48226)

M. C. Beekman

Southwest Atomic Energy Associates

(Box 1106, Shreveport, La 71102)

J. R. Welsh

United Nuclear Corporation

(Box 1583, New Haven, Conn)

A. Strasser (2)
Westinghouse Electric Corporation

(Box 158, Madison, Pa 15663)

J. C. R. Kelly, Jr. (2)

Westinghouse Electric Corporation

(Box 158, Madison, $\mathrm{Pa}$ 15663)

C. A. Anderson

Westinghouse Electric Corporation

(Westinghouse Research Laboratories

Churchill Borough, Pittsburgh, Pa 15235

E. Berky

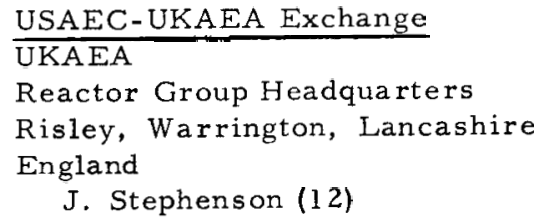

USAEC-UKAEA Exchange

UKAEA

Reactor Group Headquarters

Risley, Warrington, Lancashire

England

J. Stephenson (12)

USAEC-EURATOM Exchange

Commission des Communautes Europeennes

23-27, avenue de la Joyeuse Entree

Brussels 4, Belgium

A. deStordeur (10)

\section{CNEN}

Via Mazzini 2

Bologna, Italy

F. Pierantoni (4)

\section{CEN Saclay}

Boite Postale 2

Gif-Sur-Yvette (Set 0) France

G. Vendryes (10)

Kernforschungszentrum Karls ruhe

7500 Karlsruhe, Germany

W. Haefele (10) 